NBER WORKING PAPER SERIES

\title{
DYNAMIC OLIGOPOLY PRICING WITH ASYMMETRIC INFORMATION: IMPLICATIONS FOR HORIZONTAL MERGERS
}

\author{
Andrew Sweeting \\ Xuezhen Tao \\ Xinlu Yao \\ Working Paper 28589 \\ http://www.nber.org/papers/w28589 \\ NATIONAL BUREAU OF ECONOMIC RESEARCH \\ 1050 Massachusetts Avenue \\ Cambridge, MA 02138 \\ March 2021, Revised February 2022
}

We thank Nate Miller, Matt Weinberg, Gloria Sheu, Dan Vincent, Bob Majure, Joe Harrington, Kyle Bagwell and a number of seminar participants for valuable comments, which have been especially useful in framing the paper. This paper uses the IRI Academic Dataset (Bronnenberg, Kruger and Mela (2008)). All estimates and analysis using IRI data are the work of the authors and not IRI. This research was supported by US National Science Foundation Grant SES-1658670 (Sweeting) and National Natural Science Foundation of China Grant 72003120 (Tao). Xinlu Yao's work on this project was completed when she was a graduate student at the University of Maryland, and the paper does not reflect the views of her current employer (Amazon). All errors are our own. The views expressed herein are those of the authors and do not necessarily reflect the views of the National Bureau of Economic Research.

NBER working papers are circulated for discussion and comment purposes. They have not been peer-reviewed or been subject to the review by the NBER Board of Directors that accompanies official NBER publications.

(C) 2021 by Andrew Sweeting, Xuezhen Tao, and Xinlu Yao. All rights reserved. Short sections of text, not to exceed two paragraphs, may be quoted without explicit permission provided that full credit, including $\odot$ notice, is given to the source. 
Dynamic Oligopoly Pricing with Asymmetric Information: Implications for Horizontal Mergers Andrew Sweeting, Xuezhen Tao, and Xinlu Yao

NBER Working Paper No. 28589

March 2021, Revised February 2022

JEL No. D43,D82,L13,L41,L90

\section{ABSTRACT}

We model differentiated product pricing by firms that possess private information about seriallycorrelated state variables, such as their marginal costs, and can use prices to signal information to rivals. In a dynamic game, we show that signaling can raise prices significantly above static complete information Nash levels, even when the privately observed state variables are restricted to lie in narrow ranges. We calibrate our model using data from the beer industry, and show that

our model can explain changes in price levels, price dynamics and cost pass-through after the 2008 MillerCoors joint venture.

Andrew Sweeting

Department of Economics

University of Maryland

Tydings Hall 3135

College Park, MD 20742

and NBER

sweeting@econ.umd.edu

Xuezhen Tao

Shanghai University of Finance and Economics

318 Wuchuan Rd

Wujiaochang, Yangpu District

Shanghai 200083

China

tao.xuezhen@mail.shufe.edu.cn

\author{
Xinlu Yao \\ University of Maryland \\ Tydings Hall \\ College Park, MD 20742 \\ United States \\ xlyao0420@gmail.com
}

A data appendix is available at http://www.nber.org/data-appendix/w28589 


\section{Introduction}

Theoretical and empirical analyses of supply in differentiated product markets usually assume that firms have complete information (CI) and set prices to maximize their current profits. If an alternative is considered, it is typically tacit collusion with repeated CI stage games, which, in the empirical literature is often modeled using a "conduct parameter" (Bresnahan (1982), Lau (1982), Nevo (1998)) where each firm uses a standard CI Nash first-order conditions except that some weight is placed on the profits of its rivals. These CI formulations are tractable and, under appropriate assumptions, they are econometrically identified (Berry and Haile (2014)).

However, assuming that firms have CI about all factors that may affect their rivals' pricing choices is a strong assumption. Public companies closely guard information about the profitability of individual product lines and government agencies presume that information on revenues, costs and margins is competitively sensitive and highly confidential during antitrust investigations even while they use models that assume CI to model market outcomes. There is also surprisingly little evidence that CI oligopoly models accurately predict qualitative or quantitative changes in pricing behavior after structural changes in market conditions, such as the consummation of a merger.

It is clearly important to know whether predictions would change, in a material way, if the CI assumption is relaxed. A natural assumption for an economist is that, when firms have privately-observed state variables, a firm will try to learn from its rivals' choices (i.e., their prices) about those variables, in order to try to more accurately predict how those rivals will price in the future. If this happens, then firms may also have incentives to distort 
their prices in order to affect what their rivals will expect.

We develop models where this logic applies. Specifically, we will assume that each firm has a payoff-relevant state variable, such as its marginal cost, which is positively but imperfectly serially-correlated and unobserved by rivals. Prices are perfectly observed. We will consider fully separating equilibria where, in equilibrium, a firm's chosen price perfectly reveals its current cost, and beliefs have a simple form. In these equilibria, all firms that do not have the lowest possible marginal cost set prices above static best response levels to credibly signal this information to their rivals. This can, in turn, cause static best response prices to increase, and signaling prices to rise further, a positive feedback that can raise equilibrium prices significantly above static CI Nash levels even when there is limited uncertainty about costs, as well as generating significant price volatility. We provide examples where private information about $1 \%$ of marginal costs, which applied economists would likely view as small enough to ignore, leads to prices $10 \%$ higher than they would be under complete information. While Mailath (1989) shows that our mechanism can raise prices in a two period model, we believe that we are the first to show these effects may be large (in a two period model they are typically small), and the first to take this type of model to data.

We apply our model to horizontal mergers. When an oligopoly market becomes more concentrated, the incentives of all firms to invest in raising their rivals' prices by signaling tend to become stronger. This leads our model to typically predict larger price increases than the CI Nash models that are currently used for quantitative merger analysis. We find large effects when all firms are symmetric, and when the merging firms are different to rivals.

We calibrate our model using data from the U.S. beer market around the time of the 2008 Miller-Coors (MC) joint venture (JV). After the JV, MC and its larger domestic rival 
Anheuser-Busch (AB) increased prices by similar amounts. Miller and Weinberg (2017) (MW) show that this is inconsistent with static CI Nash behavior, which would predict that, if the merging parties raise their prices, non-merging firms would respond with smaller price increases. MW use the observed price changes to estimate a conduct parameter, interpreted as reflecting post-merger tacit collusion by domestic brewers, and Miller, Sheu and Weinberg (2020) (MSW) use the price change to calibrate a model of price leadership, in which the JV raises prices by relaxing incentive compatibility constraints.

Our calibration takes a different approach. We calibrate the parameters of our model using only pre-JV data, and show that it predicts how much $\mathrm{AB}$ and MC's prices increase after the JV, as well as several qualitative changes in price dynamics. We are not aware of previous retrospectives that have considered changes in price dynamics. If we assume that brewers have private information about the "per mile" efficiency of their distribution networks, then our model can also explain significant, and newly identified, changes in cost pass-through by the domestic brewers after the JV. In contrast, CI models, with or without changes in conduct, fail to match several patterns in the data.

The novelty of our analysis leads to several limitations which future work may relax. First, we assume that each firm has exactly one privately-known state variable and can send exactly one signal per period. This restricts the types of mergers that we can consider, although our assumptions are reasonable in our application. Second, we only consider fully separating equilibria, even though we also find that these may not exist for some parameters. Sweeting et al. (2022) consider pooling equilibria in a game where the merging parties have private information about a synergy. Third, while we present evidence against particular collusive models, collusion cannot be rejected more generally because folk theorems imply 
that some collusion model is likely to be able to explain any observed change in pricing. However, we can conclude that tacit collusion is not a necessary ingredient of an explanation for what happened in the beer data.

After a review of the related literature, Section 2 presents our model and equilibrium concept. Section 3 presents examples and illustrates the implications for merger analysis. Section 4 provides our empirical application. Section 5 concludes. Several Appendices, intended for online publication, detail our computational algorithms, additional examples, proofs of existence and uniqueness for a model with linear demand, our data and additional empirical analyses.

Related Literature. Shapiro (1986) and Vives (2011) examine how equilibrium prices and welfare change when marginal costs are private information in one-shot oligopoly models. Most of our focus will be on models where marginal costs lie in quite narrow intervals and the static effects that these papers identify are very small. A large theoretical literature has considered one-shot signaling models where only one player has private information. The classic Industrial Organization example is the Milgrom and Roberts (1982) limit pricing model, where an incumbent monopolist may lower its first period price to deter entry in a two-period game. Sweeting, Roberts and Gedge (2020) (SRG) develop finite and infinitehorizon versions of this model where an incumbent monopolist's type changes over time, as we will assume in this paper $1^{1}$ They calibrate the model and show that it can explain why incumbent airlines dropped prices by as much as $15 \%$ when Southwest threatened entry on monopoly routes.

1 Kaya (2009) and Toxvaerd (2017) analyze one-sided, dynamic signaling games where the informed firm's type is fixed, and, in equilibrium, the informed firm signals until its reputation is established. 
There are important differences between this paper and SRG, despite the common interest in signaling. Price effects are large in SRG because (i) marginal costs are estimated to be very persistent, (ii) entry causes a large permanent decrease in profits, and (iii) the assumed entry process implies that successful deterrence in one quarter can be expected to preserve monopoly for several years. The current paper considers a more common setting (pricesetting oligopoly) and a more policy relevant application (mergers). In equilibrium, a signal in one period only raises its rivals prices in the next period. Instead, we obtain quite large price effects, even with parameters that imply limited correlation in costs, because of feedbacks that exist when rivals are simultaneously signaling. These feedbacks are absent in SRG.

The literature on games where multiple players signal simultaneously is limited 2 Mailath (1988) identifies conditions under which a separating equilibrium will exist in an abstract two-period game with continuous types, and shows that the conditions on payoffs required for the uniqueness of each player's separating best response function are similar to those shown by Mailath (1987) for models where only one player is signaling (Mailath and von Thadden (2013) generalize these conditions). Mailath (1989) applies these results to a two-period pricing game where differentiated firms have static linear demands and marginal costs that are private information but fixed. Firms raise their prices in the first period in order to try to raise their rivals' prices in the second period. We rely on Mailath's results to characterize best response signaling pricing functions, and we will focus on the magnitude, empirical relevance and implications of the equilibrium effects in multi-period settings with more standard forms

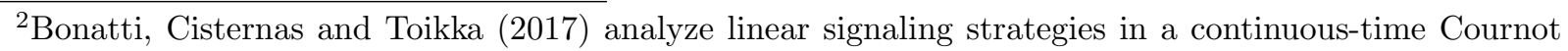
game where each firm's marginal cost is private information and fixed, but firms cannot perfectly observe the quantities that their rivals choose. We will assume that prices are perfectly observable.
} 
of differentiated product demand $!^{3}$ Mester (1992) extends this approach to a three-period quantity-setting model where marginal costs change over time, and she shows that signaling, which leads to increased output in this case, happens in the first two periods.

Fershtman and Pakes (2012) and Asker et al. (2020) take an alternative approach to dynamic games with asymmetric information. Assuming discrete states and actions, they reduce the computational burden using the concept of Experience-Based Equilibrium (EBE) where firms have beliefs about their payoffs from different actions rather than rivals' types. ${ }^{4}$ Our equilibrium concept is more standard, and the computational burden is reduced by focusing on fully separating equilibria in continuous action games.

Our paper is partly motivated by the horizontal merger retrospectives that often identify price increases after consummated mergers (Ashenfelter, Hosken and Weinberg (2014) ) and that merger simulations and other calculations that assume CI Nash, such as pricing pressure indices, predict poorly $(\text { Peters }(2009) \text { and Garmon }(2017)) !^{5}$ This leads naturally to the question of whether alternative models can do better at explaining the effects of mergers.

$\sqrt[3]{\text { Caminal }}(1990)$ considers a two-period linear demand duopoly model where firms have private information about the demand for their own product, and also raise prices to signal that they will set higher prices in the final period.

${ }^{4}$ The rest of the literature on dynamic games, following Ericson and Pakes (1995) and Pakes and McGuire (1994), has assumed that players observe all state variables, apart from iid shocks to the payoffs from different actions, eliminating any role for signaling.

5 Ashenfelter, Hosken and Weinberg (2014) note that retrospectives have not typically found price increases in banking. Interestingly, the Mester (1992) analysis of a Cournot oligopoly model with asymmetric information was explicitly motivated by a desire to explain why, contrary to the predictions of Nash and tacit collusion models, concentration appeared to lead to more competitive behavior in banking. 


\section{Model}

\subsection{Specification.}

A fixed set of $N$ risk-neutral firms play a discrete time game with periods, $t=1, \ldots, T$, where $T \leq \infty$. The discount factor is $\beta=0.99$ unless otherwise stated. If a firm sells multiple products, we will assume that they have identical demands and realized marginal costs, and are sold at a single price. There may be commonly known differences in demand and marginal costs across firms, but exactly one dimension of a firm's type is private information. All firms observe current and past prices.

We will consider two different formulations of types which we will use for different purposes. Our explanation of the model, our empirical application and several examples will assume that a firm's type can take any value on a known compact interval $\left[\underline{\theta_{i}}, \overline{\theta_{i}}\right]$. We will use a model where types can take two discrete values, $\underline{\theta_{i}}$ and $\overline{\theta_{i}}$, when we want to explore what happens for many different parameters or different numbers of firms as the computational burden is lower. In both cases, types evolve exogenously, and independently according to a first-order Markov process, $\psi_{i}: \theta_{i, t-1} \rightarrow \theta_{i, t}$. This assumption is consistent with most treatments of productivity changes in the structural production function literature following Olley and Pakes (1996).

Within-Period Timing. In each period $t$ of the game, timing is as follows. Firms enter period $t$ with their $t-1$ types, which then evolve according to $\psi_{i}$. Firms observe their own new types, but neither the previous nor the new types of other firms $]^{6}$ Each firm

\footnotetext{
${ }^{6}$ Our fully separating equilibria would be unchanged if $t-2$ types were revealed.
} 
simultaneously chooses and commits to its price, $p_{i, t}$, with no menu costs. Demand is static and time-invariant, and one period profits are $\pi_{i}\left(p_{i, t}, p_{-i, t}, \theta_{i, t}\right)$ and we assume that $\frac{\partial \pi_{i}}{\partial p_{-i, t}}>0$ for all $-i$.

Assumptions. For the continuous type game, we make the following assumption which implies types are positively, but not perfectly, serially correlated, in the sense that the likelihood of a higher type increases in the previous period's type.

Assumption 1 Type Transitions for the Continuous Type Model. The conditional $p d f \psi_{i}\left(\theta_{i, t} \mid \theta_{i, t-1}\right)$

1. has full support, so that the type can transition from any value on the support to any other value in a single period.

2. is continuous and differentiable (with appropriate one-sided derivatives at the boundaries).

3. for any $\theta_{i, t-1}$ there is some $\theta^{\prime}$ such that $\left.\frac{\partial \psi_{i}\left(\theta_{i, t} \mid \theta_{i, t-1}\right)}{\partial \theta_{i, t-1}}\right|_{\theta_{i, t}=\theta^{\prime}}=0$ and $\frac{\partial \psi_{i}\left(\theta_{i, t} \mid \theta_{i, t-1}\right)}{\partial \theta_{i, t-1}}<0$ for all $\theta_{i, t}<\theta^{\prime}$ and $\frac{\partial \psi_{i}\left(\theta_{i, t} \mid \theta_{i, t-1}\right)}{\partial \theta_{i, t-1}}>0$ for all $\theta_{i, t}>\theta^{\prime}$

We will consider fully separating equilibria where each firm will have a correct belief about each rival's previous period type. For convenience, we assume that beliefs about types in $t=1$ have the same structure.

Assumption 2 Initial Period Beliefs. Firms know what their rivals' types were in a fictitious prior period, $t=0$. 


\subsection{Fully Separating Equilibrium in a Finite Horizon and Contin- uous Type Game.}

We now describe the equilibrium for a game with two ex-ante symmetric single-product duopolists.

Final Period $(T)$. In the final period, firms use Bayesian Nash Equilibrium (BNE) strategies that maximize their expected payoffs given their own types, their beliefs about their rival's type and their rival's strategy. If firm $j$ believes that firm $i$ 's period $T-1$ type was $\widehat{\theta_{i, T-1}^{j}}$ and $j$ 's period $T$ pricing function is $P_{j, T}\left(\theta_{j, T}, \theta_{j, T-1}, \widehat{\theta_{i, T-1}^{j}}\right) \sqrt[7]{ }$, then a type $\theta_{i, T} i$ will set a price

$$
p_{i, T}^{*}\left(\theta_{i, T}, \theta_{j, T-1}, \widehat{\theta_{i, T-1}^{j}}\right)=\arg \max _{p_{i, T}} \int_{\underline{\theta_{j}}}^{\overline{\theta_{j}}} \pi\left(p_{i, T}, P_{j, T}\left(\theta_{j, T}, \theta_{j, T-1}, \widehat{\theta_{i, T-1}^{j}}\right), \theta_{i, T}\right) \psi\left(\theta_{j, T} \mid \theta_{j, T-1}\right) d \theta_{j, T} .
$$

Earlier Periods $(1, . ., T-1)$. In earlier periods, $i$ may choose not to set a static best response price in order to affect $j$ 's belief about its type. The equilibrium concept that we use is symmetric Markov Perfect Bayesian Equilibrium (MPBE) (Toxvaerd (2008), Roddie (2012)). An MPBE specifies period-specific pricing strategies for each firm $i$ as a function of its current type and beliefs, where the strategy maximizes $i$ 's payoff given the current and future pricing strategy of its rivals. It also specifies how beliefs are formed given observed pricing histories, and, on the equilibrium path, beliefs should be consistent with Bayes Rule and equilibrium pricing strategies. If there are multiple rivals, they should have consistent beliefs given an observed history. While only current types and prices are directly payoff-

\footnotetext{
${ }^{7}$ This notation reflects the fact that we are assuming that player $j$ used an equilibrium strategy in $T-1$ that revealed its type $\left(\theta_{j, T-1}\right)$, but we are allowing for the possibility that firm $i$ may have deviated so that $j$ 's beliefs about $i$ 's previous type are incorrect.
} 
relevant, history can matter in this Markovian equilibrium because of how it affects beliefs. We will only consider fully separating MPBEs where, in every period, a firm's equilibrium pricing strategy perfectly reveals its current type, and $j$ 's belief about $i$ 's current type will come from inverting $i$ 's pricing function.

Characterization of Separating Pricing Functions in Period $t<T$. We characterize fully separating pricing functions by defining a firm $i$ 's period-specific "signaling payoff function", $\Pi^{i, t}\left(\theta_{i, t}, \widehat{\theta_{i, t}^{j}}, p_{i, t}\right)$, following Mailath $(1989)$ who shows how to apply the results in Mailath (1987) to this problem. $\Pi^{i, t}$ is the present discounted value (PDV) of firm $i$ 's expected current and future payoffs when its current type is $\theta_{i, t}$, it sets price $p_{i, t}$ and $j$ believes, at the end of period $t$, that $i$ has type $\widehat{\theta_{i, t}^{j}}$. $\Pi^{i, t}$ is assumed to be continuous and at least twice differentiable in its arguments. It is implicitly conditional on (i) $j$ 's period $t$ pricing strategy, which will depend on $j$ 's beliefs about $t-1$ types, and (ii) both players' strategies in future periods. As $j$ 's end-of-period $t$ belief about $i$ 's type enters as a separate argument, $p_{i, t}$ only affects $\Pi^{i, t}$ through period $t$ profits. Given conditions on $\Pi^{i, t}$ that will be listed in a moment, the fully separating best response function of firm $i$, which is also implicitly conditioned on j's current pricing strategy and beliefs about previous types, can be uniquely characterized as follows (see Appendix C for a restatement of the Mailath (1987) theorems): $i$ 's pricing function will be the solution to a differential equation where

$$
\frac{\partial p_{i, t}^{*}\left(\theta_{i, t}\right)}{\partial \theta_{i, t}}=-\frac{\Pi_{2}^{i, t}\left(\theta_{i, t}, \widehat{\theta_{i, t}^{j}}, p_{i, t}\right)}{\Pi_{3}^{i, t}\left(\theta_{i, t}, \widehat{\theta_{i, t}^{j}}, p_{i, t}\right)}>0
$$


and a boundary condition. The subscript $n$ in $\Pi_{n}^{i, t}$ denotes the partial derivative of $\Pi^{i, t}$ with respect to the $n^{\text {th }}$ argument. Assuming that lower types want to set lower prices (e.g., a type corresponds to the firm's marginal cost $)$, the boundary condition will be that $p_{i, t}^{*}\left(\underline{\theta_{i}}\right)$ is the solution to

$$
\Pi_{3}^{i, t}\left(\underline{\theta_{i}}, \widehat{\theta_{i, t}^{j}}, p_{i, t}\right)=0
$$

i.e., the lowest type's price maximizes its static expected profits given $j$ 's pricing policy. The numerator in (1) is $i$ 's marginal future benefit from raising $j$ 's belief about $\theta_{i, t}$, and the denominator is the marginal effect of a price increase on $i$ 's current profit. For prices above a static best response price, the denominator will be negative, and the pricing function will slope upwards in the firm's type.

This characterization of a separating best response will be valid under four conditions on $\Pi^{i, t}$, in addition to continuity and differentiability,

Condition 1 Shape of $\Pi^{i, t}$ with respect to $p_{i, t}$. For any $\left(\theta_{i, t}, \widehat{\theta_{i, t}^{j}}\right), \Pi^{i, t}\left(\theta_{i, t}, \widehat{\theta_{i, t}^{j}}, p_{i, t}\right)$ has a unique optimum in $p_{i, t}$, and, for all $\theta_{i, t}$, for any $p_{i, t}$ where $\Pi_{33}^{i, t}\left(\theta_{i, t}, \widehat{\theta_{i, t}^{j}}, p_{i, t}\right)>0$, there is some $k>0$ such that $\left|\Pi_{3}^{i, t}\left(\theta_{i, t}, \widehat{\theta_{i, t}^{j}}, p_{i, t}\right)\right|>k$.

Condition 2 Type Monotonicity. $\Pi_{13}^{i, t}\left(\theta_{i, t}, \widehat{\theta_{i, t}^{j}}, p_{i, t}\right) \neq 0$ for all $\left(\theta_{i, t}, \widehat{\theta_{i, t}^{j}}, p_{i, t}\right)$.

Condition 3 Belief Monotonicity. $\Pi_{2}^{i, t}\left(\theta_{i, t}, \widehat{\theta_{i, t}^{j}}, p_{i, t}\right)$ is either $>0$ for all $\left(\theta_{i, t}, \widehat{\theta_{i, t}^{j}}\right)$ or $<0$ for all $\left(\theta_{i, t}, \widehat{\theta_{i, t}^{j}}\right)$.

Condition 4 Single-Crossing. $\frac{\Pi_{3}^{i, t}\left(\theta_{i, t}, \widehat{\theta_{i, t}^{j}}, p_{i, t}\right)}{\Pi_{2}^{i, t}\left(\theta_{i, t}, \widehat{\theta_{i, t}^{j}}, p_{i, t}\right)}$ is a monotone function of $\theta_{i, t}$ for all $\widehat{\theta_{i, t}^{j}}$ and for $\left(\theta_{i, t}, p_{i, t}\right)$ in the graph of $p_{i, t}^{*}\left(\theta_{i, t}, \theta_{j, t-1}\right)$. 
To interpret these conditions, assume that types correspond to marginal costs. The first condition will be satisfied if, for any marginal cost and distribution of prices that the rival may set, a firm's expected current period profit is quasi-concave in its own price. This will hold for common forms of differentiated product demand such as the multinomial and nested logit models. Type monotonicity requires that, when a firm increases its price, the profit that it loses will be lower if it has higher marginal costs. This will hold for constant marginal costs. Belief monotonicity requires that a firm's expected future profits should increase when rivals believe that it has a higher cost, holding its actual cost fixed. This condition may fail (Appendix B.1.2 analyzes a two-type example). Single-crossing requires that a firm with a higher marginal cost should always be more willing to raise its price, reducing its current profits, in order to raise its rivals' beliefs about its marginal cost. This condition can also fail. For completeness, we also need to define beliefs that a firm will have if the rival sets a price that is outside the range of the pricing function (i.e., a price that is not on the equilibrium path). When types correspond to marginal costs, we will assume that when a firm sets a price below (above) the lowest (highest) price in the range of the pricing function, it will be inferred to have the lowest (highest) possible cost type.

Existence and Uniqueness of a Fully Separating Equilibrium. These conditions guarantee the existence and uniqueness of fully separating best responses with continuous types, but they are not sufficient for the existence or uniqueness of a fully separating MPBE in the whole game. When marginal costs are private information, Mailath (1989) does prove existence and uniqueness in a two-period duopoly game with linear demand. Appendix $\mathrm{C}$ extends this result to a multi-period finite horizon game, assuming that the marginal cost 
interval $(\bar{\theta}-\underline{\theta})$ is small enough so that a single-crossing condition holds when prices rise. No proofs are available in infinite horizon games. In our empirical application, we will assume nonlinear demand and, to reduce the computational burden, an infinite horizon. We will therefore proceed without proofs of existence or uniqueness. Appendix A details how we compute equilibrium strategies, and verify belief monotonicity and single-crossing as part of the algorithm. We will discuss examples where we cannot find any separating equilibrium below. However, we have only ever found a single equilibrium in finite horizon games and infinite horizon games with continuous types.

In a two-type model, even best responses may not be unique. Our two-type examples therefore apply, during computation, a refinement by solving for the strategies that achieve separation at the lowest cost to the signaling firm. This is consistent with the type of "intuitive criterion" (Cho and Kreps (1987)) refinement that has been widely used in onesided signaling models with two types. However, even with the refinement, we have found examples of multiplicity in infinite horizon games with two types, so our results may be dependent on the algorithm that we use..$^{8}$

\section{$3 \quad$ Examples}

This section uses examples to illustrate the equilibrium effects of signaling, and how equilibrium prices change with the number of firms, mergers, discount factors and asymmetries.

\footnotetext{
${ }^{8}$ In infinite horizon examples where we have found multiplicity, our computational algorithm appears to consistently identify an equilibrium that is the limit, as the number of periods grows, of the equilibrium in the early periods of a finite-horizon game.
} 


\subsection{Equilibrium Strategies in a Finite Horizon, Continuous-Type Duopoly Example.}

Specification. Two ex-ante symmetric single-product firms play a finite horizon game with $T=25$ periods. There is nested logit demand, with both products in one nest, and the outside good in its own nest. Consumer c's indirect utility from buying product $i$ is $u_{i, c}=5-0.1 p_{i}+\sigma \nu_{c}+(1-\sigma) \varepsilon_{i, c}$ where $p_{i}$ is the dollar price, $\varepsilon_{i, c}$ is a draw from a Type I extreme value distribution, $\sigma=0.25$, and $\nu_{c}$ is an appropriately distributed draw for $c$ 's nest preferences. For the outside good, $u_{0, c}=\varepsilon_{0, c}$. We will set market size equal to 1 , so that our welfare numbers have a "per-potential consumer" interpretation.

Firm marginal costs are private information. For each firm, $c_{i, t}$ lies in the interval $[\underline{c}, \bar{c}]=$ $[\$ 8, \$ 8.05]$ and evolves according to an independent and exogenous truncated AR(1) process

$$
c_{i, t}=\rho c_{i, t-1}+(1-\rho) \frac{\bar{c}+\underline{c}}{2}+\eta_{i, t}
$$

where $\rho=0.8$ and $\eta_{i, t} \sim \operatorname{TRN}\left(0, \sigma_{c}^{2}, \underline{c}-\rho c_{i, t-1}-(1-\rho) \frac{\bar{c}+\underline{c}}{2}, \bar{c}-\rho c_{i, t-1}-(1-\rho) \frac{\bar{c}+\underline{c}}{2}\right)$. $\sigma_{c}=\$ 0.025 . T R N$ denotes a truncated normal distribution, whose arguments are the mean and the variance of the untruncated distribution, and the lower and upper truncation points.

We note two features of this parameterization. First, marginal costs are restricted to a narrow range (diverging by less than $0.32 \%$ from mean value) and the probability that a firm will switch from a relatively high cost to a relatively low cost within the range between periods is quite high (the probability that a firm with cost $\bar{c}$ has a cost less than $\frac{\bar{c}+\underline{c}}{2}$ in the next period is 0.32 ). This limits what can be inferred about a firm's next period marginal cost from any signal. Even though this limits signaling incentives, we find large equilibrium 
Table 1: Equilibrium Prices and Welfare in the Duopoly Game

\begin{tabular}{|c|c|c|c|c|c|c|}
\hline \multirow[b]{2}{*}{ Period } & \multirow[b]{2}{*}{$\begin{array}{l}\text { Nature of } \\
\text { Equilibrium }\end{array}$} & \multirow[b]{2}{*}{$\begin{array}{l}\text { Mean } \\
\text { Price }\end{array}$} & \multirow[b]{2}{*}{$\begin{array}{l}\text { Std. Dev. } \\
\text { Price }\end{array}$} & \multicolumn{3}{|c|}{$\frac{\text { Expected Welfare Measures }}{\text { Per Market Size Unit }}$} \\
\hline & & & & $\begin{array}{l}\text { Cons. } \\
\text { Surplus }\end{array}$ & $\begin{array}{l}\text { Producer } \\
\text { Surplus }\end{array}$ & $\begin{array}{l}\text { Total } \\
\text { Welfare }\end{array}$ \\
\hline $\mathrm{T}-24$ & MPBE & $\$ 24.76$ & $\$ 0.47$ & $\$ 30.91$ & $\$ 15.96$ & $\$ 46.87$ \\
\hline $\mathrm{T}-13$ & MPBE & $\$ 24.76$ & $\$ 0.47$ & $\$ 30.91$ & $\$ 15.96$ & $\$ 46.87$ \\
\hline $\mathrm{T}-10$ & MPBE & $\$ 24.75$ & $\$ 0.47$ & $\$ 30.92$ & $\$ 15.95$ & $\$ 46.87$ \\
\hline T-7 & MPBE & $\$ 24.68$ & $\$ 0.45$ & $\$ 30.98$ & $\$ 15.89$ & $\$ 46.88$ \\
\hline $\mathrm{T}-4$ & MPBE & $\$ 24.25$ & $\$ 0.36$ & $\$ 31.40$ & $\$ 15.51$ & $\$ 46.91$ \\
\hline T-2 & MPBE & $\$ 23.38$ & $\$ 0.17$ & $\$ 32.23$ & $\$ 14.74$ & $\$ 46.97$ \\
\hline T-1 & MPBE & $\$ 22.88$ & $\$ 0.06$ & $\$ 32.71$ & $\$ 14.29$ & $\$ 47.00$ \\
\hline $\mathrm{T}$ & BNE & $\$ 22.62$ & $\$ 0.01$ & $\$ 32.96$ & $\$ 14.05$ & $\$ 47.01$ \\
\hline $\begin{array}{l}\text { Infinite } \\
\text { Horizon }\end{array}$ & $\begin{array}{l}\text { Stationary } \\
\text { MPBE }\end{array}$ & $\$ 24.76$ & $\$ 0.47$ & $\$ 30.91$ & $\$ 15.96$ & $\$ 46.87$ \\
\hline
\end{tabular}

Notes: except for the last row, all prices are based on equilibrium strategies in a finite horizon model with parameters described in the text. The last line reports results for the stationary strategies in an infinite horizon model with the same parameters.

effects. Second, the assumed demand parameters imply high margins and limited diversion to the outside good in both static and dynamic equilibria. We will discuss how these features contribute to the existence of a fully separating equilibrium with large price effects below.

Equilibrium Outcomes and Strategies. Table 1 shows expected price levels, the standard deviation of prices and various welfare measures when we simulate data using equilibrium strategies in different periods of the finite horizon game. For comparison, expected joint-profit maximizing prices and static Nash equilibrium prices under CI (given average costs) are $\$ 45.20$ and $\$ 22.62$, with small standard deviations (\$0.007 and $\$ 0.011)$. Signaling MPBE prices are higher and more volatile than Nash prices in periods before $T-1$, although prices never approach joint-profit maximizing levels.

Figure 1(a) shows four static BNE period $T$ pricing functions for firm 2, for different 
Figure 1: Period $T$ and $T-1$ Pricing Strategies in the Finite Horizon, Continuous Type Signaling Game
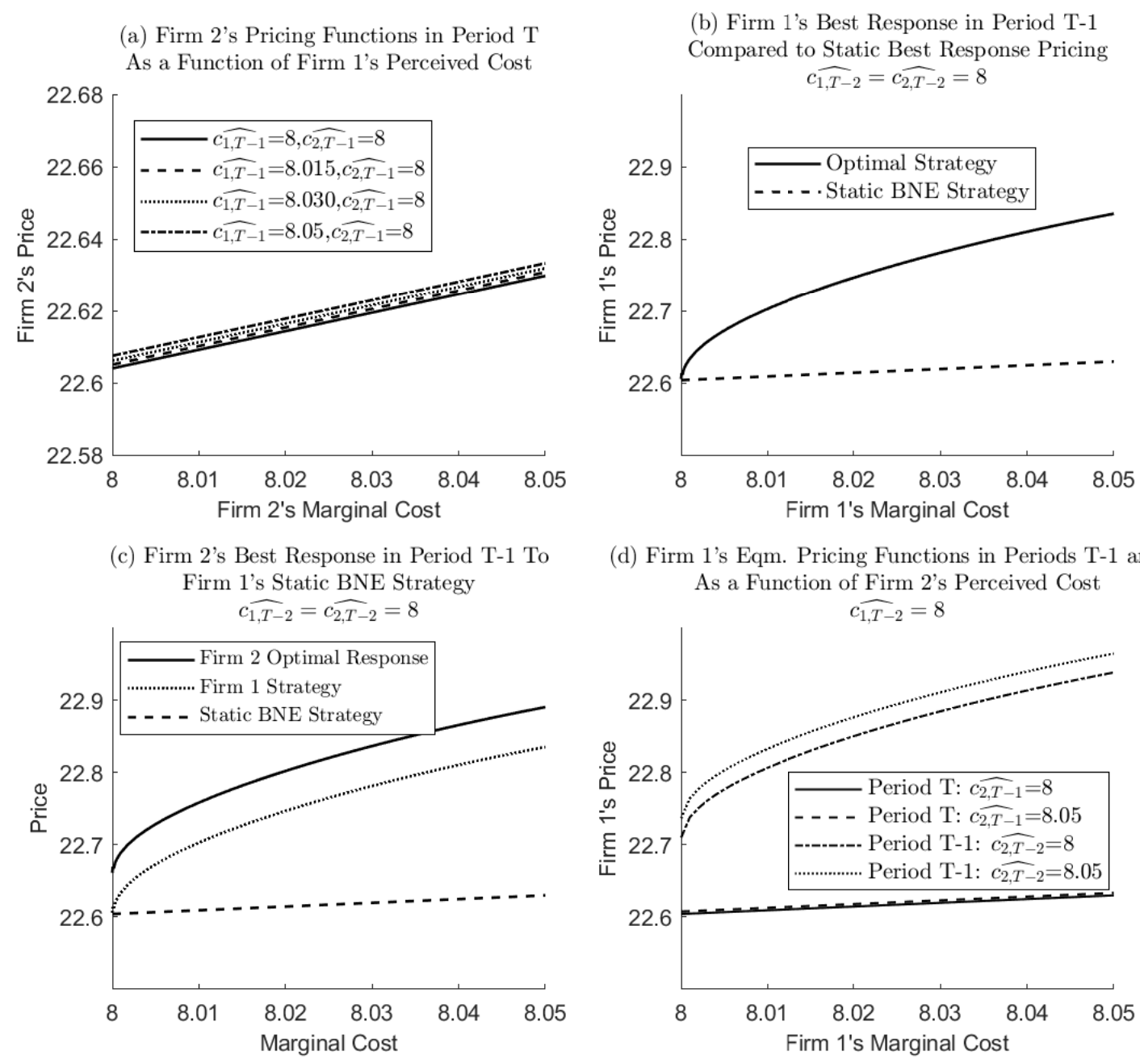

(d) Firm 1's Eqm. Pricing Functions in Periods T-1 and T

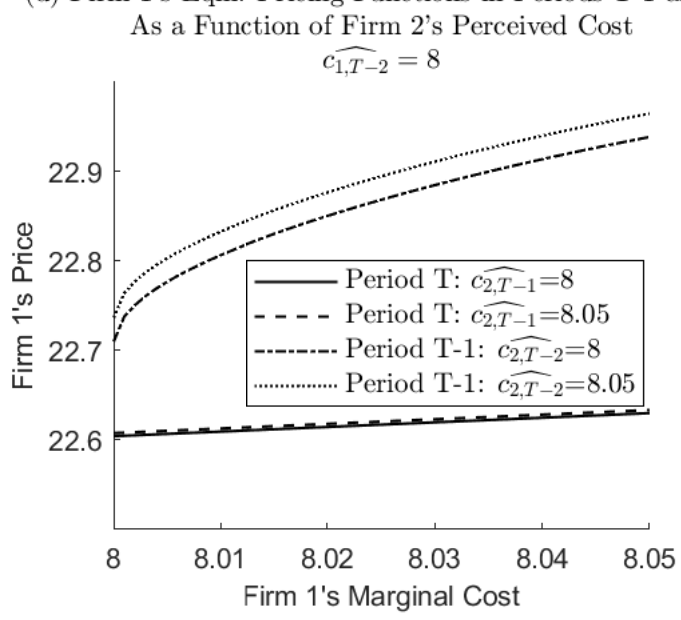

values of firm 1's period $T-1$ marginal cost $\left(c_{1, T-1}\right)$, assuming that both firms know/believe that $c_{2, T-1}=\$ 8$. Firm 2's price increases with $c_{1, T-1}$ as firm 1's expected period $T$ price rises with $c_{1, T-1}$. However, the variation in firm 1's prior cost affects firm 2's price by less than one cent, and, averaging across all possible cost realizations, average prices and welfare are almost identical to outcomes with CI 9 Therefore the existence of asymmetric information in the static period $T$ game does not generate quantitatively interesting effects.

In period $T-1$ a firm has incentive to signal to affect its rival's period $T$ price. Assuming

\footnotetext{
${ }^{9}$ Expected producer and consumer surplus differ by less than $\$ 0.0001$ across these models.
} 
Figure 2: Expected $T-1$ Period Profit Function: $c_{1, T-1}=\$ 8.025$ and $c_{1, T-2}=c_{2, T-2}=\$ 8$

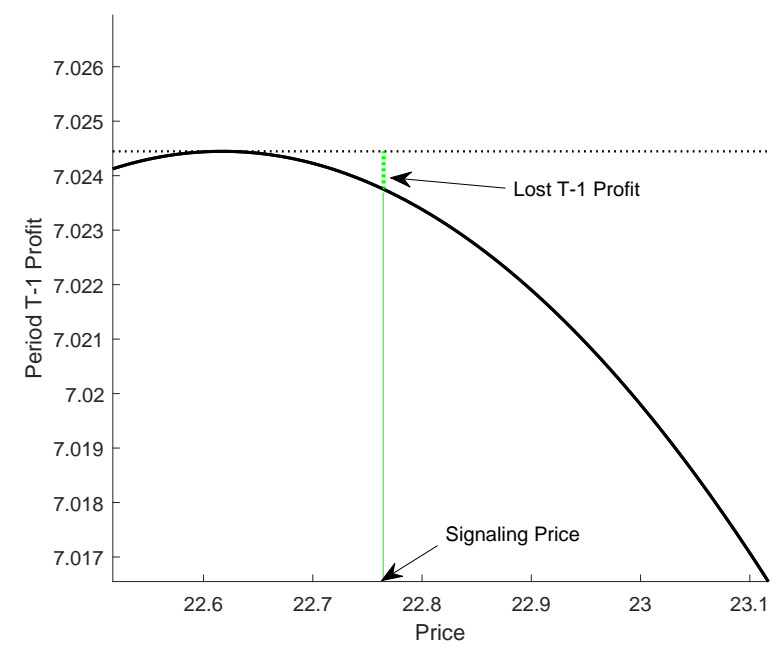

Notes: the profit function is drawn "per potential consumer" for a firm assumed to have a marginal cost of $\$ 8.025$, and with a rival using the static BNE pricing strategy when both firms' previous period marginal costs were $\$ 8$.

both firms' period $T-2$ costs were $\$ 8$, Figure 1(b) shows firm 1's signaling pricing function (found by solving the differential equation (1) given the boundary condition (2)) if it expected that firm 2 was using its period $T$ strategy. We reproduce the period $T$ pricing strategy for comparison. The pricing functions intersect for $c_{1, T-1}=\$ 8$, but signaling may lead firm 1 to raise its price by as much as 20 cents for higher costs. At first blush, this large increase may seem surprising given that we know a signal can only affect firm 2's $T$ price by a small amount. However, assumed demand implies that firm 1's profit function, shown in Figure 2 , is sufficiently flat that, if $c_{1, T-1}=\$ 8.025$, the expected reduction in $T-1$ profit from using a signaling price of $\$ 22.76$, rather than the statically optimal price, is only $\$ 0.00070$ per consumer, which is less than the expected period $T$ gain $(\$ 0.00079)$ from being viewed as a firm with $c_{1, T-1}=\$ 8.025$ rather than $c_{1, T-1}=\$ 8.0001$, which would be firm 2's belief if firm 1 set the static price.

Figure 1(b) assumed that firm 2 was using its period $T$ strategy with no signaling. 
Figure 3: Equilibrium Pricing Functions for Firm 1 in the Infinite Horizon Game and Various Periods of the Finite Horizon Game.

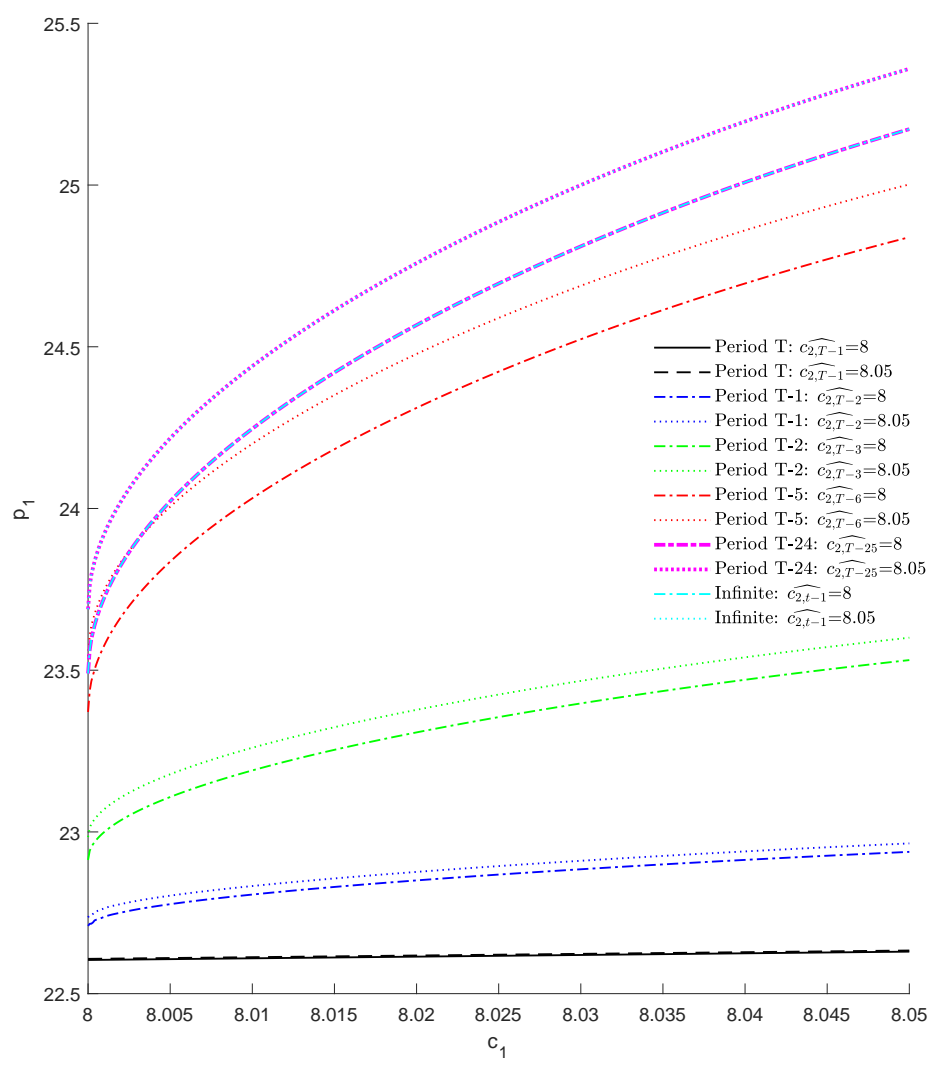

Notes: all functions drawn assuming that firm 1's perceived marginal cost in the previous period was $\$ 8$.

Figure 1(c) shows firm 2's best signaling response when firm 1 uses the strategy in Figure 1(b) (repeated in the new figure as a comparison). As firm 1's expected price has increased, firm 2's static best response pricing function shifts upwards. Of course, this positive feedback will cause firm 1's pricing function to rise as well. Figure 1(d) shows the equilibrium period $T-1$ pricing functions. The increase in the slope and the dispersion of the pricing functions means that period $T-1$ prices will be higher and more volatile than period $T$ prices.

The increased vertical spread also means that period $T-1$ prices are more sensitive to perceived period $T-2$ costs which increases period $T-2$ signaling incentives. Figure 3 shows a selection of equilibrium pricing functions for period $T-2$ and earlier periods. The pricing 
functions become more spread out and the level of prices increases, although by successively smaller amounts, in earlier periods. Further back than period $T-15$ equilibrium pricing functions and average prices barely change. The figure also plots the stationary pricing strategies that we compute for an infinite horizon game with the same parameters. They are indistinguishable from the strategies in the early periods of the finite horizon game ${ }^{10}$

\subsection{Cost Assumptions, Signaling Incentives and the Existence of Separating Equilibria.}

As noted, signaling incentives in the previous example are relatively weak because of the limited correlation in marginal costs across periods. Increasing the $\mathrm{AR}(1)$ parameter or $\bar{c}-\underline{c}$, or reducing $\sigma_{c}$, tends to increase signaling incentives and raise equilibrium prices. However, when price increases are too large, the conditions for characterizing best responses can fail and we may not be able to find a separating equilibrium.

The first six columns of Table 2 show, for different periods, the baseline average prices and average prices when signaling incentives are strengthened. Small parameter changes raise prices, but larger changes cause failures in our ability to find best response pricing functions. Pooling or partial pooling equilibria may exist, but we do not know how to characterize them. Appendix B.1.2 uses a two-type example to explain the failure of the conditions, including belief monotonicity. The final column illustrates that we can sustain separating equilibria if $\bar{c}-\underline{c}$ and $\sigma_{c}$ increase simultaneously, leaving the probability that a cost goes from one extreme of the support to the opposite half of the support unchanged at 0.32 . This is relevant for our application, where the calibrated values of $\bar{c}-\underline{c}$ and $\sigma_{c}$ are much higher

\footnotetext{
${ }^{10} \mathrm{We}$ have consistently found this convergence except in cases when the conditions required for separation are violated or are very close to being violated in which case the infinite horizon strategies may not converge.
} 
Table 2: Equilibrium Pricing in a Finite Horizon Game with Alternative Cost Specifications

\begin{tabular}{|c|c|c|c|c|c|c|c|}
\hline \multirow{3}{*}{$\begin{array}{l}{[\underline{c}, \bar{c}](\$)} \\
\sigma_{c}(\$)\end{array}$} & \multirow{2}{*}{$\frac{\text { Baseline }}{[8,8.05]}$} & \multicolumn{3}{|c|}{ Expand Range } & \multicolumn{2}{|c|}{$\frac{\text { Reduce }}{\text { Std. Deviation }}$} & \multirow{3}{*}{ 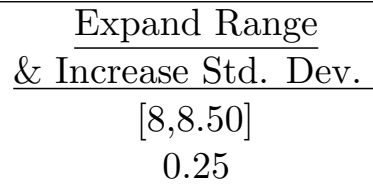 } \\
\hline & & {$[8,8.0 \overline{75]}$} & {$[8,8.15]$} & {$[8,8.3]$} & {$[8,8.05]$} & {$[8,8.05]$} & \\
\hline & 0.025 & 0.025 & 0.025 & 0.025 & 0.02 & 0.01 & \\
\hline $\mathrm{T}-24$ & $\$ 24.76$ & $\$ 26.51$ & - & - & $\$ 25.71$ & - & $\$ 24.90$ \\
\hline $\mathrm{T}-10$ & $\$ 24.75$ & $\$ 26.59$ & - & - & $\$ 25.70$ & - & $\$ 24.89$ \\
\hline T-9 & $\$ 24.74$ & $\$ 26.59$ & fails & - & $\$ 25.69$ & fails & $\$ 24.89$ \\
\hline $\mathrm{T}-8$ & $\$ 24.72$ & $\$ 26.57$ & $\$ 28.48$ & - & $\$ 25.66$ & $\$ 28.58$ & $\$ 24.89$ \\
\hline $\mathrm{T}-7$ & $\$ 24.68$ & $\$ 26.50$ & $\$ 29.17$ & fails & $\$ 25.60$ & $\$ 28.76$ & $\$ 24.87$ \\
\hline T-6 & $\$ 24.61$ & $\$ 26.37$ & $\$ 29.35$ & $\$ 30.40$ & $\$ 25.49$ & $\$ 28.65$ & $\$ 24.85$ \\
\hline $\mathrm{T}-1$ & $\$ 22.88$ & $\$ 23.05$ & $\$ 23.42$ & $\$ 23.93$ & $\$ 22.93$ & $\$ 23.05$ & $\$ 23.55$ \\
\hline $\mathrm{T}$ & $\$ 22.62$ & $\$ 22.63$ & $\$ 22.67$ & $\$ 22.74$ & $\$ 22.62$ & $\$ 22.62$ & $\$ 22.84$ \\
\hline$\infty$-Horizon & $\$ 24.76$ & $\$ 26.50$ & fails & fails & $\$ 25.71$ & fails & $\$ 24.90$ \\
\hline
\end{tabular}

Notes: values in all but the last line are based on the duopoly, continuous type, finite horizon model with demand parameters described in the text (cost parameters indicated in the table). The last line reports results for the stationary strategies in the infinite horizon model with the same parameters. "Fails" indicates that the belief monotonicity or single-crossing conditions fail so that we cannot calculate signaling best response pricing functions.

than in our baseline example.

Table 2 assumes that the cost parameters are the same for both firms. We have also solved examples where duopolists have different cost parameters, finding that changes in average prices typically depend on the parameters of the firm that has the narrowest cost interval or the least correlated costs. For example, holding our other parameters fixed, when both firms have ranges $[8,8.05]$ average equilibrium prices with signaling are $\$ 24.76$. If we drop the range of firm 2 to $[8,8.01]$ then the average prices of both firms drop to close to $\$ 22.69$ (the difference between their average prices is less than one cent), approximately 10 cents above complete information prices. These prices are almost the same as when both firms have intervals of $[8,8.01]$. We will return to this result in the context of cost pass-through in our empirical application. 


\subsection{Effects of the Number of Firms, Discount Factors and Asym- metries on Equilibrium Prices.}

We also investigate how the difference between complete information and signaling prices varies with the number of firms and demand asymmetries.

Number of Firms. Figure 4 (a) shows the average prices predicted by our signaling model and a CI model as we vary the number of firms from 2 to 7 . We use the two-type model, and each firm has a single product. We assume the same demand system as previously. Each firm's marginal cost state is either 8 or 8.05 , and changes between periods with probability 0.3. We present results using a finite horizon model, solving backwards for at least 30 periods, adding additional periods until the strategies converge 11 This guarantees that there will be a unique equilibrium in the CI game. We test whether our results are sensitive to the assumed discount factor by considering four lower values $(0.5,0.8,0.9$ and 0.95$)$ as well as 0.99 .

When $N=1$, static monopoly pricing is always optimal so all specifications predict identical prices. When $N=2$, average prices with signaling are $15.3 \%$ above CI Nash levels when $\beta=0.99$, and $9.4 \%$ higher when $\beta=0.8$, illustrating how discount factors consistent with annual, or even less frequent, pricing can generate significant effects. As $N$ increases, signaling effects diminish, as an individual firm's incentive to signal is reduced when its price will have smaller effects on the future pricing choices of other firms, and the cost of signaling is increased as the firm's demand become more elastic. However, at least until $N=6$, price effects are not trivial: for example, when $N=4$ and $\beta=0.95$, signaling prices are $2 \%$ higher than CI prices ${ }^{12}$

\footnotetext{
${ }^{11}$ Convergence is defined as a maximum difference in the pricing strategies across periods of less than 1e- 4 .

${ }^{12}$ We have also calculated average joint-profit maximizing prices under CI, and the critical discount factor
} 
Figure 4: Equilibrium Average Prices with Different Numbers of Firms and Alternative Discount Factors in a Two-Type Model, and the Effect of Demand-Side Asymmetries with Three Firms.

(a) Average Prices with Symmetric Single-Product Firms.

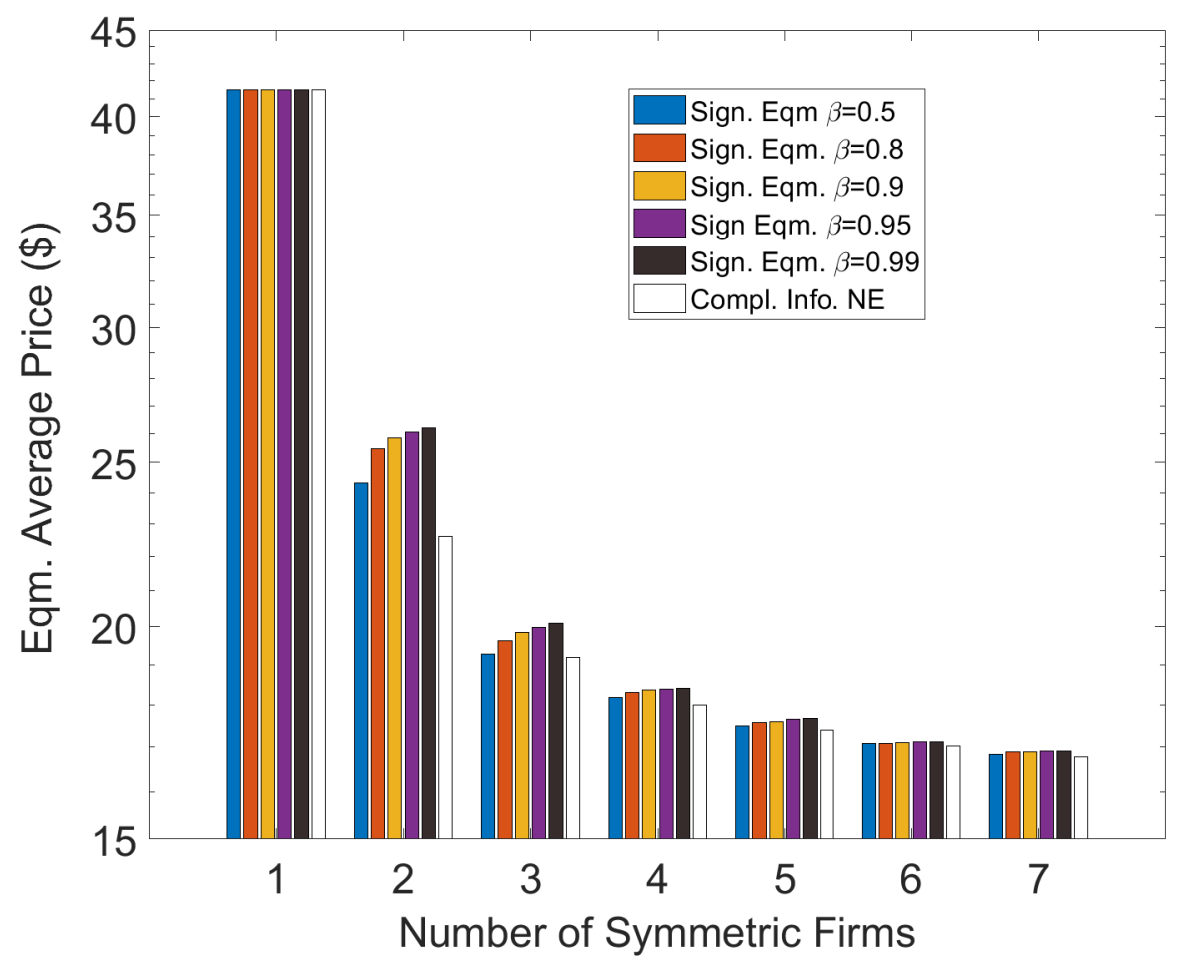

(b) Increase in Share-Weighted Average Prices Relative to CI Nash in a Three Firm Model with Demand Asymmetries.

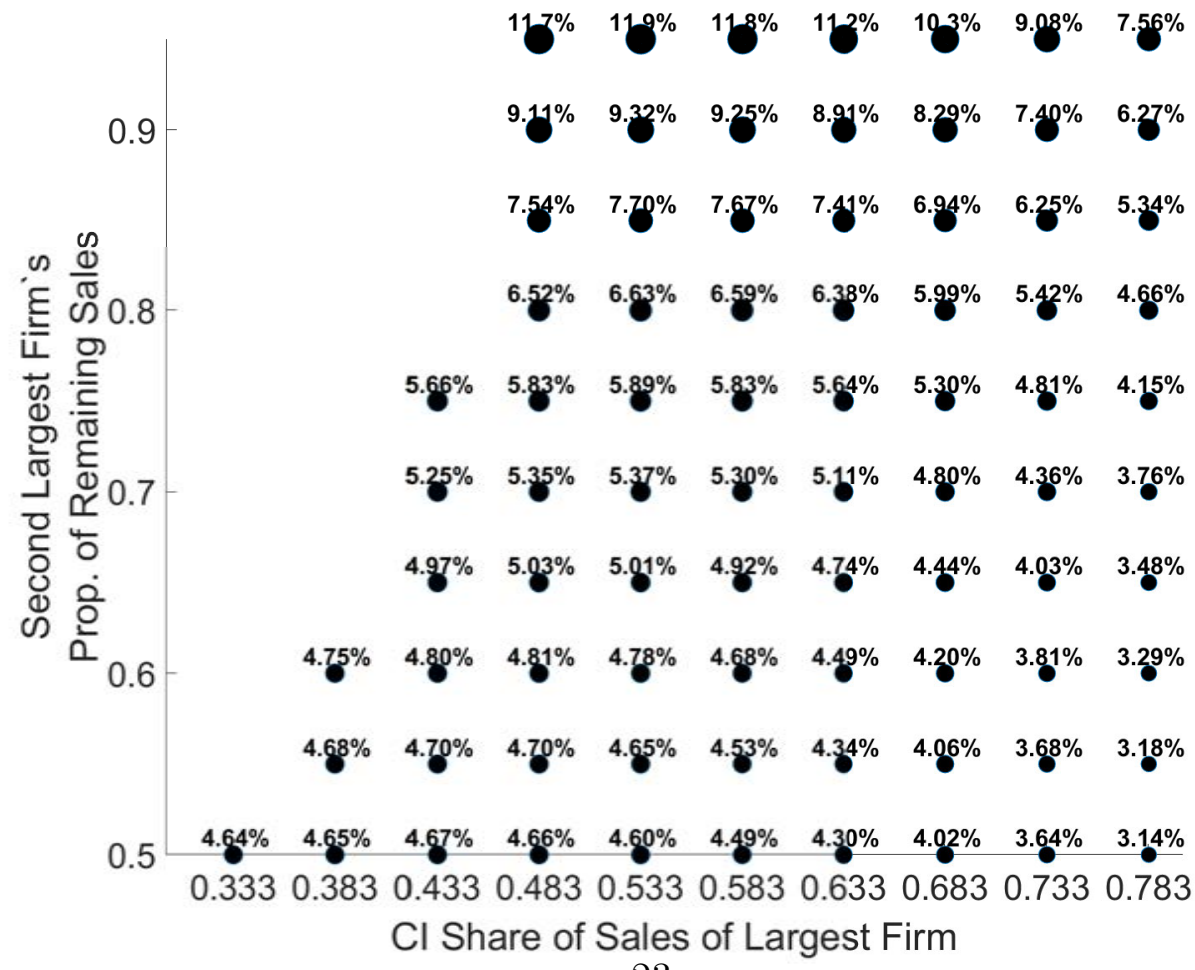


Demand Asymmetries. We use a three firm, two-type model to compare signaling and CI Nash prices when firms have asymmetric demand. We keep our previous assumptions about costs. The nesting and price demand parameters are unchanged, but we choose the firm-specific indirect utility intercepts so that, with average marginal costs for each firm and static CI Nash prices, the three firms have specific shares of sales and $97.5 \%$ of potential consumers make a purchase, implying limited substitution to the outside good.

Figure 4 (b) shows the increase in the share-weighted average price relative to CI Nash, with the circle areas indicating the magnitudes that are also written in the figure, where the share of the largest firm and the split of the shares of the other firms are represented on the axes. The price increase in the symmetric 3 -firm model is $4.6 \%$ (bottom-left circle). The percentage increases are largest when the industry is closest to an effective duopoly, but they are significant in other cases as well. For example, when the CI shares of total sales are $\{0.68,0.24,0.08\}$, average signaling prices are $5.3 \%$ higher than average CI Nash prices. In this example, it is the firm with the second largest share that increases its average price the most, in both dollar and percentage terms (10.0\%).

\subsection{Mergers and Merger Analysis.}

The previous results show that signaling leads to larger price increases when there are fewer firms. We therefore consider the effects of horizontal mergers in more detail, also motivated by how the merger simulation and pricing pressure methods used by agencies assume CI Nash pricing.

that would sustain collusion with Nash reversion trigger strategies if the game had an infinite horizon. For example, with $N=4$, joint-profit maximizing prices of over 49 could be sustained if $\beta>0.62$. 
Figure 5: Effects of an Unanticipated Merger in a Two-Type Model.

(a) Increases in Average Prices with Symmetric Single-Product Firms Before and After the Merger.

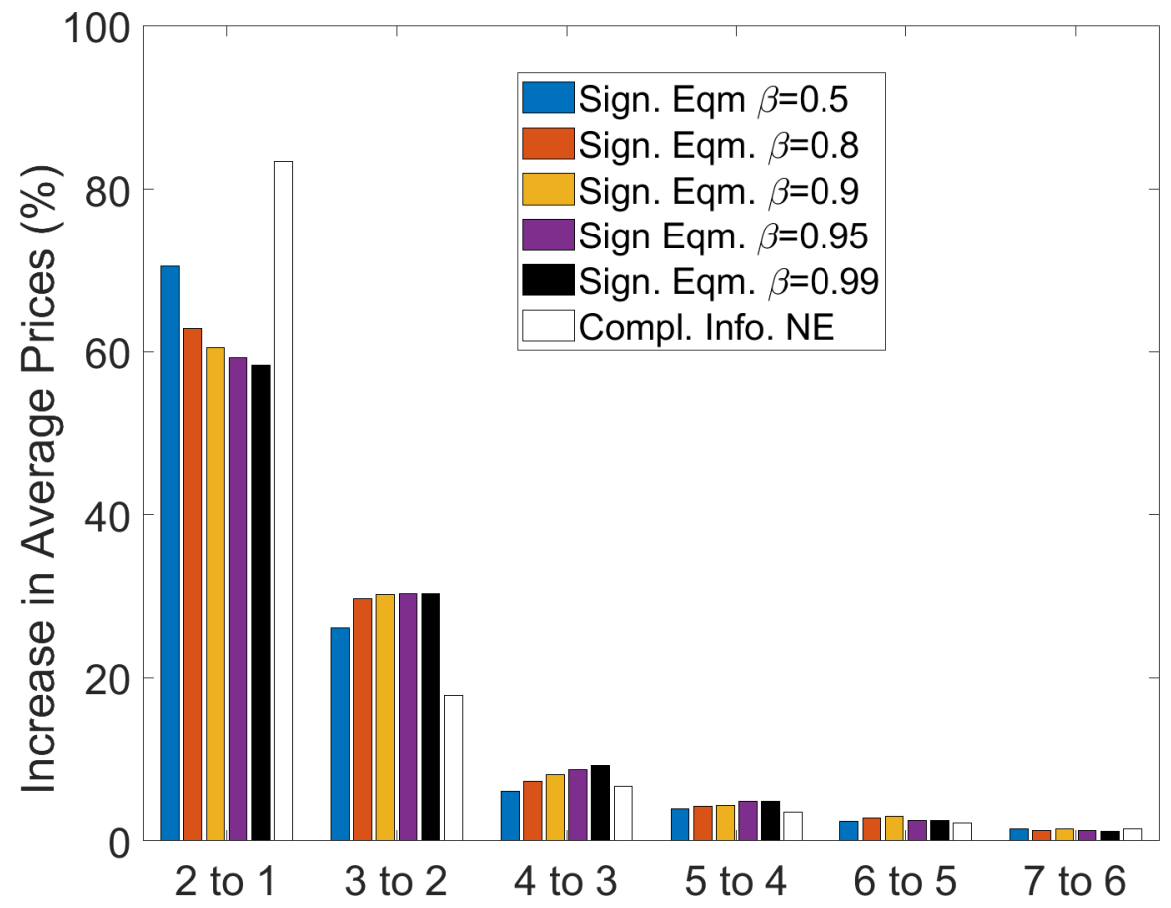

(b) Increases in Average Prices in a Four Firm Model where Merged Firm Has Two Products after the Merger and Benefits from the CI CMCR. Missing values indicate that a separating equilibrium was not found before or after the merger.

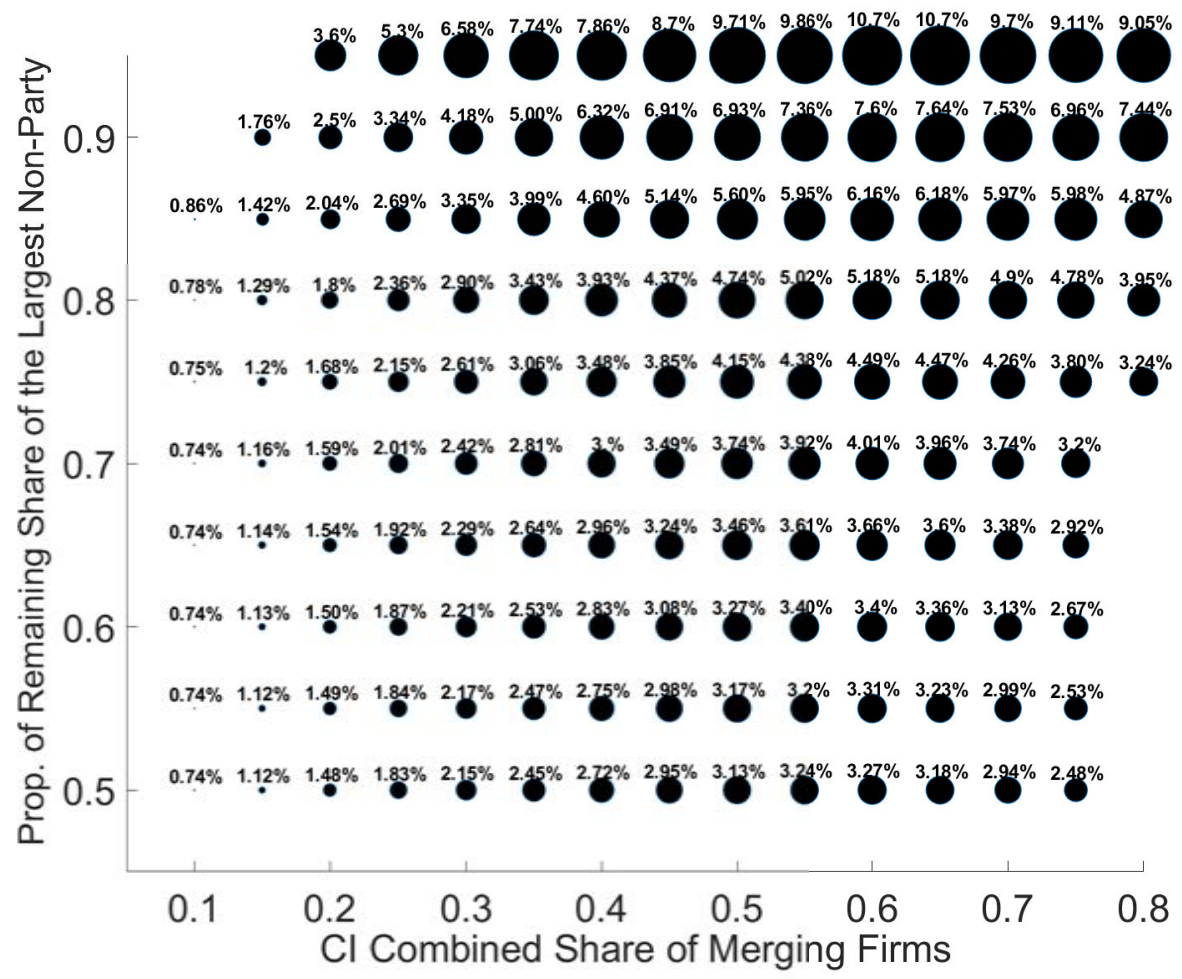


Figure 5(a) reports the increase in average firm prices after an unanticipated merger of two firms which eliminates a product without generating synergies, using the same symmetric firm specifications as Figure 4(a). As signaling has no effect on monopoly prices, CI Nash predicts the largest price increase under a merger to monopoly. Outside of this case, the signaling model predicts larger absolute post-merger price increases in all cases, and larger percentage price increases when the discount factor is large enough.

It is more common to assume that a merged firm will continue to sell both products after a merger, and that synergies are possible. As tractability requires that the merged firm's products will have identical prices and marginal costs after a merger, we will consider mergers between symmetric single product firms, but allows rivals to be asymmetric. We will also assume that the width of the cost interval and the evolution process for costs remain the same, even if marginal cost levels change due to a synergy.

Figure 5(b) shows how signaling increases share-weighted average prices (across all firms) after mergers in asymmetric 4-firm industries. The pre-merger model extends the example used for Figure 4(b) to an additional firm. The x-axis indicates the combined (CI Nash) market share of the two symmetric merging firms before the merger (so 0.5 means that each firm makes $25 \%$ of sales), while the y-axis shows the split of the remaining CI sales between the two remaining firms. We assume that the merged firm's average marginal costs decrease by the Compensating Marginal Cost Reduction (CMCR) implied by a CI Nash model, so that, under that model, equilibrium prices would not change. The price increases in the figure would therefore be unanticipated by an agency using a CI Nash analysis.

After a merger in a symmetric four-firm industry, signaling increases prices by $3.13 \%$. The size of the price increase is much larger when one of the non-merging firms has a much 
Table 3: Post-Merger Prices and Required Synergies in an Infinite Horizon Continuous-Type Model. Firms are symmetric before the merger, and the merged firm sells two products after the merger.

\begin{tabular}{|c|c|c|}
\hline & 4-to-3 Merger & 3-to-2 Merger \\
\hline Pre-Merger Average Prices & $\$ 18.25$ & $\$ 19.79$ \\
\hline $\begin{array}{l}\text { Post-Merger Average Price of Merged } \\
\text { Firm if No Marginal Cost Synergy }\end{array}$ & $\$ 21.53(+18.0 \%)$ & $\$ 27.18(+37.3 \%)$ \\
\hline $\begin{array}{l}\text { Post-Merger Average Price of Non- } \\
\text { Merging Firm if No Marginal Cost Synergy }\end{array}$ & $\$ 19.12(+4.8 \%)$ & $\$ 23.59(+19.2 \%)$ \\
\hline CI CMCR & $\$ 4.95$ & $\$ 10.08$ \\
\hline $\begin{array}{l}\text { Merged's Firm Post-Merger Average Price with } \\
\text { CI CMCR Synergy in Signaling Equilibrium }\end{array}$ & $\$ 18.85(+3.2 \%)$ & $\$ 23.00(+16.2 \%)$ \\
\hline $\begin{array}{l}\text { Marginal Cost Reduction Required to Keep Merged } \\
\text { Firm's Average Price from Rising in Signaling Equilibrium }\end{array}$ & $\$ 5.76$ & $\$ 19.94$ \\
\hline
\end{tabular}

Notes: parameterization described in the text. Note that the CI CMCR is the marginal cost reduction that an analyst would compute using the true demand system, observed (signaling) pre-merger signaling prices and a CI Nash assumption.

larger market share (the upper rows in the figure). The intuition is that, when the prices of the merging products become more sensitive to both the merged firm's costs and the prices set by rivals, the prices of a dominant rival will also become significantly more sensitive, creating a feedback that can lead to substantial equilibrium price effects. A feature of our model is that, after a merger with a synergy, the prices of non-merging firms can rise as much or more than those of the merging firms, which will not happen in a static CI Nash model where the static best response functions have slopes less than one. For example, if pre-merger sale shares are $\{0.325,0.325,0.33,0.02\}$, the equilibrium average prices of the merging products rise by $10.6 \%$, and the large rival increases its average price by $12.9 \%$. The small rival's average price increases by $1 \%$.

These patterns also imply that, if firms use signaling strategies, synergies may need to 
be much larger than the CMCRs to prevent average prices from rising ${ }^{13}$ We illustrate by extending our infinite horizon continuous-type model to allow for up to four firms, with our previous demand and cost assumptions. Firms are symmetric before the merger, but, after the merger, the merged firm has two products. Table 3 shows the effects of 4 -to-3 and 3-to-2 mergers. With no synergy, either merger leads to both the merging firms and the non-merging firms increasing their prices substantially. Very large synergies are required to prevent the merged firm's price from rising. For a 3-to-2 merger, the merged firm's average marginal cost would have to fall from $\$ 8.025$ to $-\$ 11.915$, i.e., an essentially impossible reduction.

\subsection{Additional Examples.}

Appendix B describes additional examples. For instance, Appendix B.1.1 uses the two-type duopoly model to examine the relationship between the existence of separating equilibria, the effects of signaling on prices, the serial correlation of costs and the extent to which, when a firm's price rises, demand is diverted to the outside good. The results suggest that the degree of diversion to the outside good is critical to both the existence of signaling equilibria and the magnitude of signaling effects.

Appendix B.2 shows that price effects can also be substantial when each firm's marginal cost is fixed and known, but some other state variable that affects payoffs is unobserved and serially correlated (e.g., a feature of demand or the weights that a manager places on firm profits and revenues). Our results therefore extend beyond the case of uncertain marginal costs.

\footnotetext{
${ }^{13}$ In a CI Nash model, CMCR synergies will keep the prices of all firms at their pre-merger levels. With signaling, even if a synergy keeps the average prices of the merged firm at their pre-merger level, the prices of the non-merging rivals may increase. In the example we consider here, we just focus on the average prices of the merged firm.
} 


\section{Empirical Application: The MillerCoors Joint Ven- ture}

In this section, we test whether our model can explain changes in price levels, and price dynamics in the U.S. beer industry around the time of the $2008 \mathrm{MC}$ JV, which was an effective merger of the second- and third-largest US brewers ${ }^{14}$ Section 4.1 motivates our analysis of this setting, and Section 4.2 explains our calibration of our model, and a CI alternative, using only pre-JV data. Section 4.3 compares our calibrated model's predictions to changes observed after the JV. In order to keep our discussion focused on our model, details of the data, which is the same as used by MW, demand estimation and additional analysis of CI collusive supply models are contained in Appendix D.

\subsection{Motivation.}

We choose the MC JV as our application for two broad reasons. First, key features are consistent with the assumptions that we have to make for tractability. Specifically, we model competition between AB, Miller and Coors, as firms selling single products before the JV, with Miller and Coors having symmetric demands, and we assume Miller and Coors have identical costs and prices after the JV. These three firms dominated the "subpremium" and "premium" segments of the beer industry, and there is no empirical evidence that post-JV retail price increases for the domestic brands caused significant substitution to higher-priced imported or craft beer alternatives (Appendices D.3 and D.5). The leading merging brands, Miller Lite (ML) and Coors Light (CL), had very similar national market shares and retail

\footnotetext{
${ }^{14}$ Anheuser-Busch was purchased by InBev in 2008. Throughout this section and the Appendices, we will use $\mathrm{AB}$ to refer to Anheuser-Busch before 2008 and Anheuser-Busch InBev afterwards, and we will assume that this transaction had no effect on AB's pricing incentives.
} 
Figure 6: Average Prices for Flagship Brand 12-Packs in Three Markets. Panels (a)-(c) show nominal weekly average prices for 48 months around the JV, excluding sales at temporary price reductions.

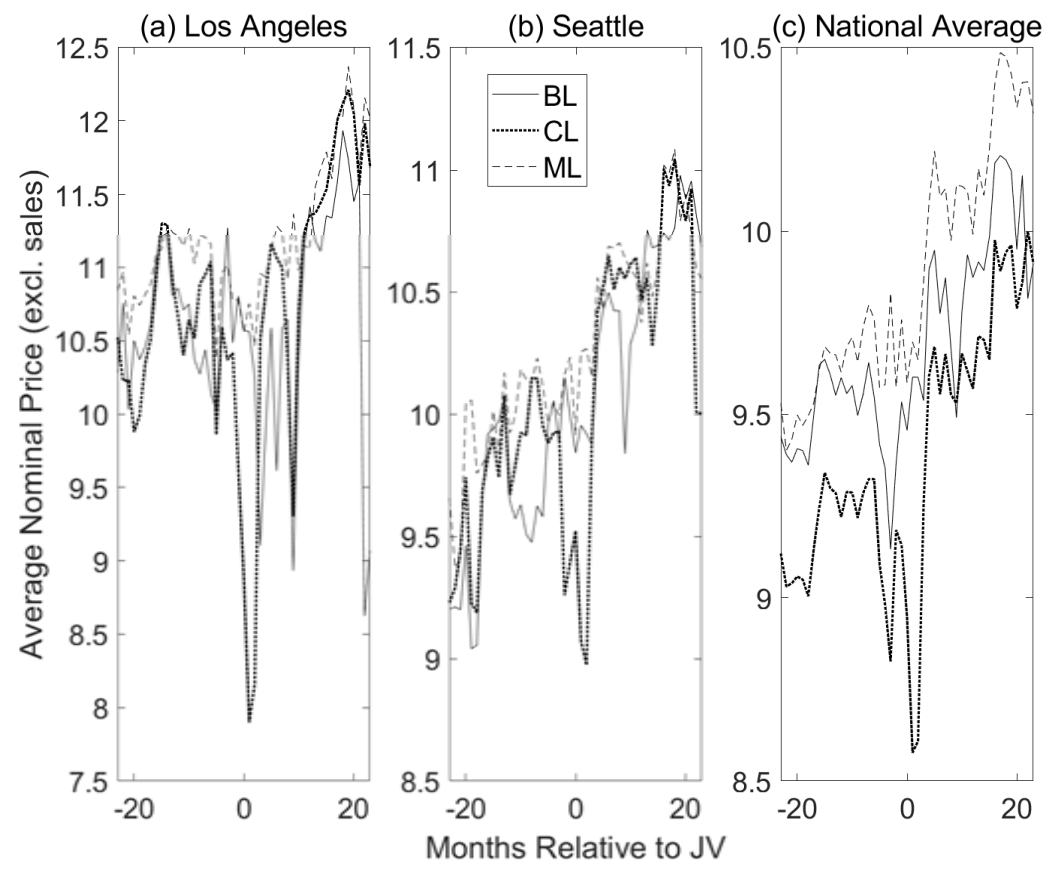

prices before the JV (Appendix D.3), and, while the largest brewers sell many products, their retail prices tend to be highly correlated (Appendix D.6). After the JV, MC produced ML and CL in the same breweries, and, in most markets, their prices were more correlated than before the JV, as can be seen in Figure6(a)-(c) (see Appendices D.6 and D.7 for alternative measures).

Second, there are several features of the price data that our model can potentially explain, some of which are inconsistent with the tacit collusion models that have been applied to this data. The first feature, identified by MW, is the similar increase in the real prices of all domestic brands, including AB's, after the MC JV despite plausible efficiencies Ashenfelter, Hosken and Weinberg (2015)) that a CI analysis would have expected to offset price increases. Regressions in Appendix D.4 quantify these price increases to lie between 40 cents and a 
dollar per 12-pack, or 3\%-6\%, depending on the specification. 15 As discussed in Section 3.4. our model can explain why non-merging firms increase their prices as much, or more, than non-merging firms. Of course, a model of collusion could also explain this fact, but, as we discuss below, there are features of the data that the specific collusion models considered in the literature cannot explain.

The second and third features are serial correlation and volatility in average retail prices both before and after the JV. Figure 6(a)-(c) show monthly average nominal retail prices (calculated as dollar sales divided by units sold) for Bud Light (BL), ML and CL 12-packs in two local markets and nationally. We present nominal prices so that the picture is not distorted by the drop in the CPI deflator (footnote 15). Sales at prices indicated as temporary price reductions are excluded when calculating the series, as these may create volatility that does not reflect changes in wholesale prices. Appendix D.7 presents alternative price measures. Appendix Figure D.6 shows that the marginal cost residuals implied by MW's preferred CI supply model are also volatile and serially correlated. In our model, some volatility in marginal costs can lead to significantly greater volatility in prices, as well as an increase in price levels and volatility after the JV. In contrast, tacit collusion models tend to imply price rigidity (Athey, Bagwell and Sanchirico (2004)).

The fourth feature is an apparent change in the rate of pass-through of transportation costs after the JV. Suppose that distribution costs equal trucking distance multiplied by a "per mile" measure of distribution network efficiency, reflecting, for example, average capacity utilization in each truck, which is private information and evolves over time. Our

\footnotetext{
${ }^{15}$ The interpretation of this price increase is potentially complicated by a fall in the CPI-U deflator, from 220.0 in July 2008 to 210.2 in December 2008, that occurred simultaneously with the merger being consummated.
} 
model would predict that, after a merger that strengthens signaling incentives, the prices of all signaling firms may increase more in markets that are located further from breweries. This signaling effect could counteract efficiencies created by the JV reducing transportation distances for some markets.

Table 4 reports price regressions that we use to measure changes in pass-through. The sample, which includes 13 brands made by domestic brewers and two importers, Grupo Modelo and Heineken, is the same as the one used in MW's Tables II and III, except that we include additional pack sizes (18- and 36-packs, which account for more than $20 \%$ of domestic brewer sales by volume) and we exclude the June 2008-May 2009 period, which MW exclude in their Table II, in all regressions. Observations are at the brand-size-market-month level and the dependent variable is the real price (in dollars) per 12-pack equivalent, and, for comparison purposes, it is useful to keep in mind that the JV increased real domestic prices by 40 cents to one dollar per 12-pack. Appendix D.10 shows that the results are similar using a log price specification. All specifications include date fixed effects, and various combinations of product and market fixed effects, but measure distances in different ways.

The first column estimates how the brewery-to-market trucking distance, measured in thousands of miles, affects retail prices before and after the JV, controlling for pre-/post-JV product (i.e., brand-size) fixed effects, market fixed effects and date fixed effects. We estimate pre- and post-JV distance coefficients for imported products and each domestic brewer. The coefficients show that domestic prices were significantly more sensitive to distance after the JV, while this is not the case for imported products. The coefficients are also quite large given that, for example, the average post-JV distance for Miller is 316 miles with standard deviation 269 miles, and a range of over 1,000 miles. As there is little evidence 
Table 4: Distance Pass-Through Regressions: Real Price Per 12-Pack for all Pack Sizes

\begin{tabular}{|c|c|c|c|c|c|c|c|}
\hline $\begin{array}{l}\text { Distance } \\
\text { Measure }\end{array}$ & $\begin{array}{c}(1) \\
\text { Own }\end{array}$ & $\begin{array}{c}(2) \\
\text { Own } \times \\
\text { Diesel }\end{array}$ & $\begin{array}{c}(3) \\
\text { Own }\end{array}$ & $\begin{array}{c}(4) \\
\text { Min. } \\
\text { Domestic }\end{array}$ & $\begin{array}{l}(5) \\
-\end{array}$ & $\begin{array}{c}(6) \\
\text { Own }\end{array}$ & $\begin{array}{c}(7) \\
\text { Min. } \\
\text { Domestic }\end{array}$ \\
\hline \multicolumn{8}{|c|}{ Distance Measure $\times$} \\
\hline $\mathrm{AB}$ & $\begin{array}{l}-0.319 \\
(0.180)\end{array}$ & $\begin{array}{l}-0.059 \\
(0.068)\end{array}$ & & & & & \\
\hline Imports & $\begin{array}{c}0.470 \\
(0.185)\end{array}$ & $\begin{array}{c}0.109 \\
(0.043)\end{array}$ & & & & & \\
\hline Coors & $\begin{array}{c}0.194 \\
(0.067)\end{array}$ & $\begin{array}{c}0.109 \\
(0.021)\end{array}$ & & & & & \\
\hline Miller & $\begin{array}{l}-0.143 \\
(0.102)\end{array}$ & $\begin{array}{l}0.008 \\
(0.038)\end{array}$ & & & & & \\
\hline \multicolumn{8}{|c|}{ Post-JV $\times$ Own Distance $\times$} \\
\hline$\overline{\mathrm{AB}}$ & $\begin{array}{c}0.629 \\
(0.314)\end{array}$ & $\begin{array}{c}0.197 \\
(0.102)\end{array}$ & $\begin{array}{c}0.569 \\
(0.313)\end{array}$ & $\begin{array}{c}0.868 \\
(0.232)\end{array}$ & & $\begin{array}{c}0.290 \\
(0.304)\end{array}$ & $\begin{array}{c}0.635 \\
(0.275)\end{array}$ \\
\hline Imports & $\begin{array}{l}-0.198 \\
(0.189)\end{array}$ & $\begin{array}{l}-0.064 \\
(0.042)\end{array}$ & $\begin{array}{l}-0.132 \\
(0.160)\end{array}$ & $\begin{array}{l}0.305 \\
(0.249)\end{array}$ & & $\begin{array}{l}-0.221 \\
(0.168)\end{array}$ & $\begin{array}{c}0.076 \\
(0.277)\end{array}$ \\
\hline Coors & $\begin{array}{c}0.560 \\
(0.144)\end{array}$ & $\begin{array}{l}0.156 \\
(0.047)\end{array}$ & $\begin{array}{c}0.718 \\
(0.134)\end{array}$ & $\begin{array}{c}0.789 \\
(0.200)\end{array}$ & & $\begin{array}{c}0.611 \\
(0.133)\end{array}$ & $\begin{array}{c}0.538 \\
(0.246)\end{array}$ \\
\hline Miller & $\begin{array}{c}0.796 \\
(0.149)\end{array}$ & $\begin{array}{c}0.233 \\
(0.042)\end{array}$ & $\begin{array}{c}0.785 \\
(0.152)\end{array}$ & $\begin{array}{c}0.905 \\
(0.228)\end{array}$ & & $\begin{array}{c}0.686 \\
(0.137)\end{array}$ & $\begin{array}{c}0.662 \\
(0.266)\end{array}$ \\
\hline \multicolumn{8}{|l|}{ Post-JV $\times$} \\
\hline \multicolumn{5}{|c|}{$\overline{\text { Reduction Coors Distance }}$} & $\begin{array}{l}-0.377 \\
(0.201)\end{array}$ & $\begin{array}{c}-0.443 \\
(0.196)\end{array}$ & $\begin{array}{l}-0.360 \\
(0.212)\end{array}$ \\
\hline \multicolumn{5}{|c|}{ Mkt HHI Increase Due to JV } & $\begin{array}{c}2.327 \\
(2.731)\end{array}$ & $\begin{array}{l}2.330 \\
(2.652)\end{array}$ & $\begin{array}{c}2.147 \\
(2.810)\end{array}$ \\
\hline \multicolumn{8}{|c|}{ Post-JV × Domestic $\times$} \\
\hline \multicolumn{5}{|c|}{$\overline{\text { Reduction Coors Distance }}$} & $\begin{array}{l}-0.078 \\
(0.133)\end{array}$ & $\begin{array}{c}0.126 \\
(0.137)\end{array}$ & $\begin{array}{c}0.047 \\
(0.144)\end{array}$ \\
\hline \multicolumn{5}{|c|}{ Mkt HHI Increase Due to JV } & $\begin{array}{c}3.019 \\
(2.554)\end{array}$ & $\begin{array}{c}2.633 \\
(2.401)\end{array}$ & $\begin{array}{c}1.810 \\
(2.179)\end{array}$ \\
\hline Fixed Effects & $\begin{array}{c}\text { Pre/Post } \times \\
\text { Product } \\
\text { Market }\end{array}$ & $\begin{array}{c}\text { Pre/Post } \times \\
\text { Product } \\
\text { Market }\end{array}$ & $\begin{array}{c}\text { Product } \times \\
\text { Market } \\
\text { Pre/Post } \times \\
\text { Product }\end{array}$ & $\begin{array}{c}\text { Product } \times \\
\text { Market } \\
\text { Pre/Post } \times \\
\text { Product }\end{array}$ & $\begin{array}{c}\text { Product } \times \\
\text { Market } \\
\text { Pre/Post } \times \\
\text { Product }\end{array}$ & $\begin{array}{c}\text { Product } \times \\
\text { Market } \\
\text { Pre/Post } \times \\
\text { Product }\end{array}$ & $\begin{array}{c}\text { Product } \times \\
\text { Market } \\
\text { Pre/Post } \times \\
\text { Product }\end{array}$ \\
\hline Observations & 191,909 & 191,909 & 191,909 & 191,909 & 191,909 & 191,909 & 191,909 \\
\hline R-squared & 0.927 & 0.926 & 0.957 & 0.957 & 0.957 & 0.957 & 0.957 \\
\hline
\end{tabular}

Notes: standard errors, clustered on the market, in parentheses. See text for discussion of the sample. Date fixed effects in all specifications. 
of significant demand substitution to imported products, we view the imported brands as providing a comparison group whose signaling incentives may not have changed after the JV. We interpret the coefficients as being consistent with the domestic firms engaging in signaling about network efficiency, with incentives to signal becoming stronger after the JV.

In column (2), we use distance multiplied by the real price of diesel as the distance measure. Average real diesel prices in the two years before and after the JV were very similar. While the scale of the coefficients changes, the pattern remains the same. The remaining columns use distance-only based measures, although the results are qualitatively similar using the distance $\times$ diesel price variable.

Column (3) includes product-market fixed effects, and the post-JV distance coefficients should be interpreted as reflecting how post-JV price increases vary with trucking distances ${ }^{16}$ Even though there are no distance changes for $\mathrm{AB}$ products after the JV, and for only a small number of markets for Miller products, the coefficients imply that the size of price increases are related to trucking distances for these firms, and not for imports.

As noted in Section 3.2, price increases in the signaling model are often most sensitive to the smallest range of cost uncertainty for the firms playing the game. Column (4) therefore uses the smallest trucking distance for the domestic brewers as the distance measure. The magnitude of the AB coefficient increases in size and significance.

MW estimate regressions where post-JV price increases depend on the JV-induced trucking distance reduction for Coors products and the increase in market HHI (measured between 0 and 1). The values of the HHI are higher in our analysis because we include additional

\footnotetext{
${ }^{16}$ In the MW data there are handful of small distance changes for markets before the JV, and the post-JV distance coefficients are unchanged if additional pre-JV distance coefficients are estimated.
} 
pack sizes that are primarily sold by the domestic brewers. Specification (5) show that these variables are correlated with price changes for all products, although these effects are not systematically different for domestic and imported products. Specifications (6) and (7) repeat specifications (3) and (4), but including these variables. Five out of six domestic own and minimum distance coefficients continue to be significant.

One might ask whether the increased sensitivity of pricing to own distance could be explained by a model of tacit collusion, as well as our model. For instance, more collusive conduct might potentially change the rate of cost pass-through. We investigate this possibility by taking the marginal costs implied by MW's supply-side conduct model estimates (specifically their monthly RCNL-1 model in Table VI), and regressing them on post-JV distance measures for each brewer with brand-size-market, brand-size-post JV and date fixed effects. The specification is therefore similar to Table 4 col. (3), except that the dependent variable is implied marginal costs (in real dollars), rather than real retail prices. If changes in conduct determined the change in distance pass-through then the post-JV $\times$ distance coefficients should now be zero. Instead, the Miller, Coors and AB coefficients are 0.433 (s.e. $0.171), 1.414(0.466)$ and $0.430(0.394)$ respectively. Therefore, MW's estimated change in conduct is not sufficient to explain the change in pass-through.

One can also show that other features of the MW conduct model and MSW's price leadership model can be rejected. For example, Appendix D.12 extends MW's supply-side analysis to provide evidence against MW's assumption of Nash pricing before the MC JV and MSW's assumption of incentive-compatible domestic supermarkups. Of course, a different collusive model might explain the changes in pass-through and the changes in price dynamics that we describe below. One might also argue that only a collusive model is consistent with 
remarks, cited by the Department of Justice (DOJ), in AB's Conduct Plan that describe its pricing as aiming to create "consistent and transparent competitive response" and to achieve the "highest level of followership." 17 We do not agree with this interpretation. In our model, price signals are motivated by a desire to affect rivals' future prices, and signaling relies on rivals interpreting and responding to signals appropriately. It is notable that there is no mention of the Conduct Plan discussing the types of threatened punishments that collusive models rely on.

\subsection{Calibration of the Dynamic Asymmetric Information Model.}

We calibrate an infinite horizon, continuous marginal cost three-firm/product version of our model to match several moments in the pre-JV data. We also calibrate a CI model that assumes that firms use static Nash pricing strategies. We limit the computational burden by treating local markets as different repetitions of the same game, rather than as games with different cost and demand primitives ${ }^{18}$

Products. We model the pricing of three brands, which we label BL, ML and CL. We calibrate the cost parameters to match the prices and price dynamics of these flagship products, but the prices of brands within a firm's portfolio (e.g., Budweiser and BL) are highly correlated (Appendix D.6) so one can interpret the products are representing domestic brewers' portfolios. Products of other brewers are included in the outside good 19

\footnotetext{
${ }^{17}$ See https : //www . justice.gov/atr/case-document/file/486606/download.

${ }^{18}$ Computationally light two-step approaches, which are often used to estimate dynamic games, require that all serially-correlated state variables, which in our setting would include beliefs, are observed by the researcher.

${ }^{19}$ In an earlier version of this paper we calibrated a model that included imports as a non-signaling fringe in a separate nest. The calibrated model predicted that their prices changed by around 1 cent when the JV raised domestic prices by 70 cents or more.
} 
Demand. We assume static, time-invariant nested logit demand, with the three brands in the same nest. For our baseline specification, the four parameters (the nesting and price parameters, and the mean utility intercepts of BL and ML/CL) are chosen so that, at average real pre-JV prices ( $\$ 10.09$ for BL and $\$ 9.95$ for ML/CL), the market shares of BL and ML/CL are $28 \%$ and $14 \%$, the average own price elasticity is -3 and, when a brand's price increases, $85 \%$ of the demand that it loses is diverted to the two remaining brands 20 The implied nesting and price parameters are 0.772 and -0.098 , and the BL and ML/CL mean utilities are 1.044 and 0.863 respectively. We will also calibrate specifications with alternative price elasticities and diversions, but Appendix D.11 presents estimates from richer demand models that are consistent with our assumed baseline values.

Marginal Costs. The marginal costs of brand $i, c_{i, t}$, are assumed to lie on an interval $\left[\underline{c_{i}}, \underline{c_{i}}+c^{\prime}\right]$ and to evolve according to an $\operatorname{AR}(1)$ process

$$
c_{i, t}=\rho c_{i, t-1}+(1-\rho) \frac{\underline{c_{i}}+\underline{c_{i}}+c^{\prime}}{2}+\eta_{i, t}
$$

where $\eta_{i, t} \sim T R N\left(0, \sigma_{c}^{2}, \underline{c_{i}}-\rho c_{i, t-1}-(1-\rho) \frac{\underline{\underline{c_{i}}+\frac{c_{i}}{2}+c^{\prime}}}{2}, \underline{c_{i}}+c^{\prime}-\rho c_{i, t-1}-(1-\rho) \frac{\underline{\underline{c_{i}}}+\frac{\underline{c}_{i}}{2}+c^{\prime}}{2}\right) . \sigma_{c}$ is the standard deviation of the untruncated innovation distribution. We calibrate the five parameters $\underline{c_{B L}}, \underline{c_{M L / C L}}, c^{\prime}, \rho$ and $\sigma_{c}$. We have also fitted a model where $\rho, \sigma_{c}$ and $c^{\prime}$ vary across BL and ML/CL, but this only improves the fit slightly.

Objective Function, Matched Statistics and Identification. We calibrate the cost parameters using indirect inference (Smith (2008)). For a given guess, we solve the model

\footnotetext{
${ }^{20}$ These assumed shares overstate the share of BL relative to ML and CL, but understate the share of AB, relative to Miller and Coors, in the beer market and the light beer segment.
} 
(see Appendix A.2) and simulate time-series of prices to calculate six statistics/regression coefficients that we match to equivalent statistics from the data. The objective function to be minimized is $g(\theta)^{\prime} W g(\theta) . g(\theta)$ is a vector where each element $k$ has the form $g_{k}=$ $\frac{1}{M} \sum_{m} \tau_{k, m}^{d a t a}-\widehat{\tau_{k}(\theta)}$ where $\tau_{k, m}^{d a t a}$ is the statistic estimated from the observed data and $\widehat{\tau_{k}(\theta)}$ is its simulated data equivalent. Our reported results use identity weighting matrices $W$, although, because we match all of the moments almost exactly, alternative $W$ s give similar calibrated parameters. Minimization uses fminsearch in MATLAB (version 2018a), which takes between 12 and 24 hours. Standard errors are calculated treating different markets before the JV as independent observations on the same game.

The six data statistics are calculated using series of average prices from each geographic market from January 2001 to the announcement of the JV in October 2007. Our baseline specification uses weekly data and the five most common pack sizes $(6,12,18,24$ and 30packs) ${ }^{21}$ Market-week-brand-size average real prices per 12-pack equivalent are calculated excluding temporary store price reductions, and using only market-weeks where we observe more than five stores. The first two statistics that we match are prices for BL and ML, averaged across pack sizes and weeks. The third statistic is a measure of the dispersion of $\mathrm{BL}$ prices, calculated as the interquartile range of the market-specific residuals from a regression where we regress average BL market-week-size prices on dummies for the specific set of stores observed in the market-week (interacted with pack size), to control for fixed cross-store differences in retail prices, and week-size fixed effects, to control for national promotions.

\footnotetext{
${ }^{21}$ Our model does not have different pack sizes, market heterogeneity, varying sets of stores or time trends, so the regressions using simulated data do not control for these factors. See Appendix D.2 for a discussion of the sample selection.
} 
Table 5: Pre-JV AR(1) Price Regressions Using Prices for All Pack Sizes for Flagship Brands, Excluding Temporary Price Reductions

\begin{tabular}{lccc}
\hline \hline & $(1)$ & $(2)$ & $(3)$ \\
Dep. Var & $p_{B L, t}$ & $p_{M L, t}$ & $p_{C L, t}$ \\
\hline$p_{B L, t-1}$ & 0.451 & 0.056 & 0.043 \\
& $(0.033)$ & $(0.017)$ & $(0.010)$ \\
$p_{M L, t-1}$ & 0.030 & 0.409 & 0.016 \\
& $(0.011)$ & $(0.036)$ & $(0.014)$ \\
$p_{C L, t-1}$ & 0.027 & 0.021 & 0.461 \\
& $(0.012)$ & $(0.015)$ & $(0.040)$ \\
Mean Price (\$) & 10.08 & 9.95 & 9.94 \\
SD Residuals (\$) & 0.184 & 0.221 & 0.197 \\
& & & 36,700 \\
Observations & 36,659 & 36,670 & 0.978 \\
R-squared & 0.979 & 0.972 & . \\
\hline \hline
\end{tabular}

Notes: include time period $\times$ pack size interactions and fixed effects for the set of stores in the sample. Dependent variable is the market-week average average price for a specific pack size (sizes containing volumes equivalent to $6,12,18,24$ and $3012 \mathrm{oz}$. containers included). Data from January 2001 to the announcement of the JV. Standard errors, clustered on the market, are in parentheses. The "SD Residuals" statistic is the standard deviation of the residuals from the regression.

The remaining statistics are coefficients from market-brand-specific regressions where weekly brand-size prices are regressed on the lagged prices of all three brands, dummies for the specific set of stores observed in the market-week (interacted with pack size) and a linear time trend. We match the averages of $\rho_{m}^{M L, M L}$ and $\rho_{m}^{C L, C L}, \rho_{m}^{B L, C L}$ and $\rho_{m}^{B L, M L}$, and $\rho_{m}^{M L, C L}$ and $\rho_{m}^{C L, M L}$.

Table 5 shows the coefficients from a similar regression that pools data from all markets for our baseline sample (weekly, 5 pack sizes, excluding temporary price reductions). The serial correlation own-price coefficients are between 0.41 and 0.46 , while the cross-product coefficients are positive but smaller. We will also calibrate our model using alternative samples (see Appendix D.8 for the corresponding regressions). If we include temporary price reductions, the own-price coefficients fall, consistent with many price reductions lasting only one week, and the coefficients are larger if we use only 12-packs. When we use monthly data 
we can no longer include fixed effects for the specific set of stores in the sample, so we instead use market fixed effects. This causes the correlation coefficients to increase, which leads, as we note later, to our calibrated model implying stronger signaling incentives. Appendix D.8 also shows that when we estimate market-specific coefficients, we tend to estimate larger own- and cross-product coefficients in markets where the three largest domestic firms have a larger combined share of the beer market. While our calibration ignores this variation, this pattern is consistent with our model as serial correlation in simulated data tends to increase when there is less substitution to the outside good, as one would expect when the signaling firms have higher market shares.

Assuming that our model has a unique equilibrium, the intuition for the identification of the cost parameters is straightforward. ${ }^{22}$ Given the assumed demand parameters and the observed price levels, the mark-ups implied by the model will identify the lower bounds on brand marginal costs. The $\operatorname{AR}(1)$ coefficients and the dispersion of prices will identify the range of costs and the parameters of the cost innovation process. We will compare additional statistics that are not targeted to understand the fit of the model. We also calibrate the cost-side parameters of a model where firms use CI Nash strategies using the same procedure and moments.

\footnotetext{
${ }^{22}$ The possibility that our game has multiple equilibria may create two issues for estimation. First, the objective function may be hard to minimize if our solution algorithm jumps between different sections of the equilibrium correspondence. In practice, we can match our moments almost exactly across many alternative parameterizations. Second, another equilibrium supported by different parameters might give similar predictions to the equilibrium that our algorithm finds. This is essentially a potential identification problem. Here we have to rely on the fact that we have never found multiple equilibria in continuous-type games, although we suspect that they may exist for some parameters.
} 
Table 6: Calibrated Parameters for Seven Specifications.

\begin{tabular}{lccccccc}
\hline \hline & $(1)$ & $(2)$ & $(3)$ & $(4)$ & $(5)$ & $(6)$ & $(7)$ \\
Model & Signal & Signal & Signal & Signal & Signal & Signal & CI Nash \\
Data Frequency & Week & Week & Week & Week & Week & Month & Week \\
Sizes & All & 12 only & All & All & All & All & All \\
Temp. Price Red. & Excl. & Excl. & Incl. & Excl. & Excl. & Excl. & Excl. \\
Mean Brand Price Elasticity & -3 & -3 & -3 & -2.5 & -3.5 & -3 & -3 \\
Mean Flagship Diversion & $85 \%$ & $85 \%$ & $85 \%$ & $90 \%$ & $80 \%$ & $85 \%$ & $85 \%$ \\
\hline Lower Bound Cost for BL & $\$ 5.259$ & $\$ 5.278$ & $\$ 4.845$ & $\$ 4.248$ & $\$ 5.973$ & $\$ 4.616$ & $\$ 5.439$ \\
$\left(c_{B L}\right)$ & $(0.222)$ & $(0.048)$ & $(0.046)$ & $(0.043)$ & $(0.026)$ & $(0.127)$ & $(0.010)$ \\
L.B. Cost for ML/CL & $\$ 6.426$ & $\$ 6.528$ & $\$ 5.984$ & $\$ 5.786$ & $\$ 6.874$ & $\$ 5.711$ & $\$ 6.631$ \\
$\left(c_{M L / C L}\right)$ & $(0.094)$ & $(0.014)$ & $(0.022)$ & $(0.024)$ & $(0.017)$ & $(0.020)$ & $(0.058)$ \\
Width Cost Interval & $\$ 0.600$ & $\$ 0.752$ & $\$ 1.246$ & $\$ 0.556$ & $\$ 0.672$ & $\$ 1.793$ & $\$ 0.672$ \\
$\left(\overline{c_{i}}-c_{i}\right)$ & $(0.043)$ & $(0.021)$ & $(0.018)$ & $(0.102)$ & $(0.026)$ & $(0.037)$ & $(0.097)$ \\
Cost AR $(1)$ Parameter & 1.178 & 0.939 & 0.850 & 1.222 & 0.959 & 0.742 & 1.088 \\
$(\rho)$ & $(0.028)$ & $(0.011)$ & $(0.026)$ & $(0.013)$ & $(0.012)$ & $(0.025)$ & $(0.038)$ \\
SD Cost Innovations & $\$ 0.262$ & $\$ 0.278$ & $\$ 0.566$ & $\$ 0.260$ & $\$ 0.270$ & $\$ 0.400$ & $\$ 0.278$ \\
$\left(\sigma_{c}\right)$ & $(0.031)$ & $(0.001)$ & $(0.050)$ & $(0.104)$ & $(0.026)$ & $(0.052)$ & $(0.086)$ \\
\hline \hline
\end{tabular}

Notes: $\mathrm{BL}=\mathrm{Bud}$ Light, $\mathrm{ML}=$ Miller Lite and $\mathrm{CL}=$ Coors Light. Standard errors in parentheses. The data specifications using weekly data include group-of-store fixed effects when calculating the data statistics. For the monthly specification, the regression using the data only include market fixed effects. Flagship diversion refers to the proportion of lost demand that switches to the other two products when the price of one of the product increases.

\subsection{Calibration Estimates and Counterfactuals}

Parameter Estimates and Model Fit. Table 6 reports the calibrated parameters for six signaling models, where different demand parameters are assumed or different price series are matched. Column (1) is our baseline signaling model specification and column (7) shows the calibrated parameters for a CI specification that uses the same inputs. The estimated $\sigma_{c}$ in column (1) implies that the probability that a firm may transition from the highest marginal cost to below the mean cost is 0.24 , which is similar to the 0.32 we used in our examples, even though the width of the cost support is wider. As the CI Nash model does not have the feature that signaling exaggerates what cost volatility implies for price volatility, the estimated CI model has a wider calibrated support for costs and slightly more volatile 
Table 7: Model Fit for Three Specifications Using Weekly Data, Average Brand Price Elasticity of -3 and Flagship Diversion of $85 \%$

\begin{tabular}{|c|c|c|c|c|c|}
\hline \multirow{4}{*}{$\begin{array}{l}\text { Data Freq. } \\
\text { Pack Sizes } \\
\text { Temp. Price Red. }\end{array}$} & \multicolumn{3}{|c|}{ Week } & \multicolumn{2}{|c|}{ Week } \\
\hline & \multicolumn{3}{|c|}{ All } & \multicolumn{2}{|c|}{ 12-Packs Only } \\
\hline & \multicolumn{3}{|c|}{ Excluded } & \multicolumn{2}{|c|}{ Excluded } \\
\hline & Data & Signal. Model & CI Model & Data & Signal Model \\
\hline & \multicolumn{5}{|c|}{ Targeted Moments } \\
\hline Mean $p_{B L}$ & $\$ 10.09$ & $\$ 10.09$ & $\$ 10.09$ & $\$ 10.30$ & $\$ 10.30$ \\
\hline Mean $p_{M L}$ & $\$ 9.96$ & $\$ 9.96$ & $\$ 9.96$ & $\$ 10.22$ & $\$ 10.22$ \\
\hline Mean $\rho^{M L, M L}, \rho^{C L, C L}$ & $0.402,0.413$ & 0.408 & 0.407 & $0.468,0.450$ & 0.444 \\
\hline Mean $\rho^{B L, M L}, \rho^{B L, C L}$ & $0.082,0.066$ & 0.074 & -0.000 & $0.102,0.056$ & 0.076 \\
\hline Mean $\rho^{M L, C L}, \rho^{C L, M L}$ & $0.051,0.036$ & 0.046 & 0.005 & $0.065,0.026$ & 0.035 \\
\hline \multirow[t]{2}{*}{$\mathrm{IQR} p_{B L}$} & $\$ 0.189$ & $\$ 0.189$ & $\$ 0.189$ & $\$ 0.185$ & $\$ 0.212$ \\
\hline & \multicolumn{5}{|c|}{ Non-targeted Moments } \\
\hline Mean $p_{C L}$ & $\$ 9.95$ & $\$ 9.97$ & $\$ 9.97$ & $\$ 10.20$ & $\$ 10.23$ \\
\hline$\rho^{B L, B L}$ & 0.444 & 0.403 & 0.412 & 0.442 & 0.418 \\
\hline Mean $\rho^{M L, B L}, \rho^{C L, B L}$ & $0.059,0.0 .42$ & 0.038 & -0.002 & $0.065,0.040$ & 0.038 \\
\hline $\mathrm{SD}$ of BL Res. & $\$ 0.177$ & $\$ 0.107$ & $\$ 0.111$ & $\$ 0.136$ & $\$ 0.122$ \\
\hline SD of ML/CL Res. & $\$ 0.204, \$ 0.189$ & $\$ 0.156$ & $\$ 0.139$ & $\$ 0.161, \$ 0.149$ & $\$ 0.179$ \\
\hline IQR $p_{M L}, p_{C L}$ & $\$ 0.222, \$ 0.210$ & $\$ 0.273$ & $\$ 0.250$ & $\$ 0.228, \$ 0.206$ & $\$ 0.316$ \\
\hline Skewness of BL Res. & -0.361 & -0.353 & -0.005 & -0.307 & -0.314 \\
\hline ML/CL Res. & $-0.100,-0.329$ & -0.331 & -0.004 & $-0.296,-0.201$ & -0.297 \\
\hline
\end{tabular}

Notes: $\mathrm{BL}=$ Bud Light, $\mathrm{ML}=$ Miller Lite and $\mathrm{CL}=$ Coors Light. $\mathrm{SD}=$ standard deviation. Res. = residuals from the AR(1) regressions. The calculation of the data statistics is explained in Section 4.2, with the model predictions based on simulating 10,000 periods of data. For the data we report separate values for the statistics for ML and CL, but, because the model assumes that ML and CL are symmetric, and so predicts identical statistics (ignoring simulation error), we match the average of these values during estimation and report a single prediction.

cost innovations. As one would expect, when we assume more elastic demand, the levels of calibrated marginal costs increase, and, when we include temporary price reductions in our price series, calibrated costs become more volatile.

Table 7 reports the fit of the model for the column (1), (2) and (7) specifications. The upper half of the table shows the targeted moments, which the signaling models match accurately. The CI model predicts that the cross-brand $\rho$ s should be close to zero. The lower half reports non-targeted moments, including the skewness of the innovations from the $\mathrm{AR}(1)$ regression, which is higher-order than the targeted moments. The signaling models 
Table 8: Predicted Average Prices Before and After the MC JV For Signaling Model

\begin{tabular}{lcccccc}
\hline \hline & $(1)$ & $(2)$ & $(3)$ & $(4)$ & $(5)$ & $(6)$ \\
Frequency & Week & Week & Week & Week & Week & Month \\
Sizes & All & 12 only & All & All & All & All \\
Price Reductions & Excl. & Excl. & Incl. & Excl. & Excl. & Excl. \\
Brand Elasticity & -3 & -3 & -3 & -2.5 & -3.5 & -3 \\
Flagship Diversion & $85 \%$ & $85 \%$ & $85 \%$ & $90 \%$ & $80 \%$ & $85 \%$ \\
\hline Pre-JV Mean Prices & & & & & & \\
BL & $\$ 10.09$ & $\$ 10.30$ & $\$ 9.81$ & $\$ 10.09$ & $\$ 10.09$ & $\$ 10.09$ \\
ML/CL & $\$ 9.96$ & $\$ 10.22$ & $\$ 9.68$ & $\$ 9.96$ & $\$ 9.96$ & $\$ 9.95$ \\
Assumed ML/CL Marginal & $-\$ 1.18$ & $-\$ 1.20$ & $-\$ 1.14$ & $-\$ 1.50$ & $-\$ 0.94$ & $-\$ 1.17$ \\
Cost Change & & & & & & \\
Post-JV Mean Prices & & & & & & \\
BL & $\$ 10.62$ & $\$ 10.90$ & $\$ 10.17$ & $\$ 10.98$ & $\$ 10.42$ & fails \\
ML/CL & $(+5.3 \%)$ & $(+5.7 \%)$ & $(+3.7 \%)$ & $(+8.7 \%)$ & $(+3.3 \%)$ & \\
& $\$ 10.48$ & $\$ 10.79$ & $\$ 10.02$ & $\$ 10.82$ & $\$ 10.27$ & fails \\
$(+5.8 \%)$ & $(+3.5 \%)$ & $(+8.5 \%)$ & $(+3.1 \%)$ & \\
\hline \hline
\end{tabular}

Notes: $\mathrm{BL}=$ Bud Light, $\mathrm{ML}=$ Miller Lite and $\mathrm{CL}=$ Coors Light. For the data we report separate values for the statistics for ML and CL, but, because the model assumes that ML and CL are symmetric, and so predicts identical statistics (ignoring simulation error), we report a single prediction.

match all of the moments well, apart from some underprediction of the standard deviation of price equation residuals for BL. The CI model fails to match the skewness of price innovations, as well as the $\rho^{M L, B L}$ and $\rho^{C L, B L}$ coefficients.

Predicted Effects of the JV and Comparison to Observed Outcomes. We re-solve our model assuming that the JV benefits from a synergy that would keep its average prices from rising in a CI Nash model, as this appears consistent with the DOJ's expectation, and that its owns two brands that it can produce with an identical marginal cost, and which it sells at the same price. We assume that $c_{B L}, \rho, c^{\prime}$ and $\sigma_{c}$ do not change.

Table 8 shows the predicted prices for each brand before and after the JV for the six signaling model specifications. Our synergy assumptions mean that our CI model would predict no price changes. Consistent with what was observed, the price increases in columns 
Figure 7: Bud Light Equilibrium Pricing Strategies (for estimates in column (1) of Table 6).

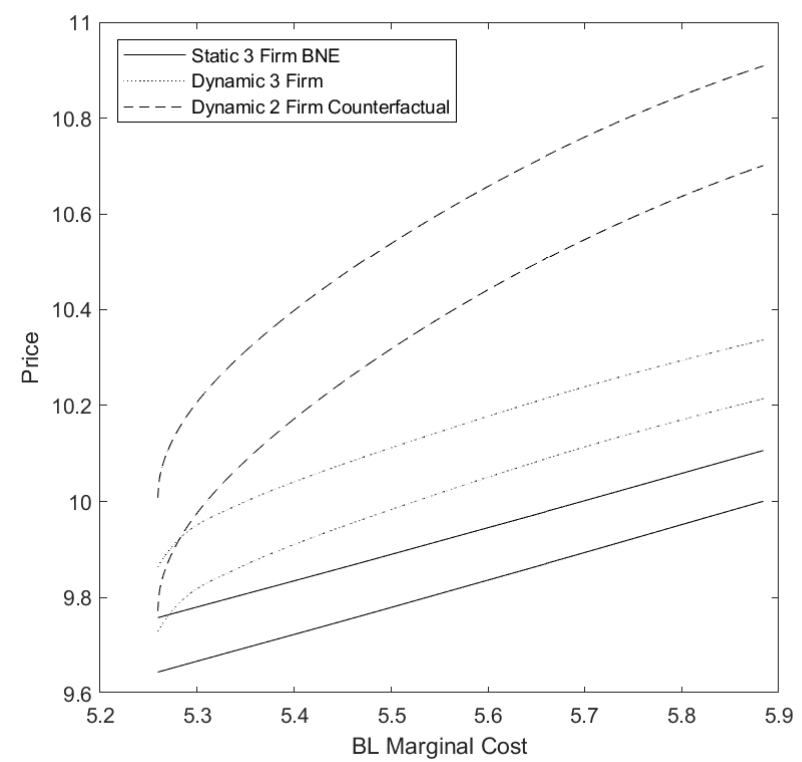

Notes: the strategies shown assume that $c_{t-1}^{B L}=\underline{c^{B L}}$ and $c_{t-1}^{M L}=c_{t-1}^{C L}=\underline{c^{M L / C L}}$ (lower line) and $c_{t-1}^{B L}=\overline{c^{B L}}$ and $c_{t-1}^{M L}=c_{t-1}^{C L}=\overline{c^{M L / C L}}$ (upper line). Therefore, for each type of equilibrium, the maximum range of BL's prices spans from the lowest point on the bottom line to the highest point on the upper line.

(1)-(5) are above $3 \%$ and they are similar for the merging brands and BL. We have also found that these predicted changes are robust to alternative assumptions about the discount factor, as these alternatives also change the calibrated parameters. ${ }^{23}$ The conditions required for separating strategies are violated in the monthly data counterfactual because the parameters, which are calibrated to price series that do not control for cross-store differences in retail pricing, imply stronger signaling incentives.

Figure 7 compares, based on the column (1) parameters, BL's equilibrium pricing strategies for the static Bayesian Nash 3-firm model, the estimated signaling 3-firm model and the counterfactual post-JV model. Even though BL's costs are unchanged, the greater responsiveness of ML/CL pricing causes BL's prices to rise and become more volatile. The change

\footnotetext{
${ }^{23}$ For example, we recalibrated and recomputed column (1) assuming a weekly $\beta=0.998$, rather than $\beta=0.99$, consistent with an annual discount factor of around 0.9 . The predicted post-JV prices are within 1 cent of those reported in Table 8 .
} 
Table 9: Observed and Predicted Changes in Price Dynamics for Calibrated Signaling Model (Table 6, col 1) and the Calibrated CI Model (Table 6, col 7) with a Conduct Parameter $(\theta=0.15)$ to Predict the Same Change in Average Prices.

\begin{tabular}{|c|c|c|c|c|c|c|c|c|c|}
\hline & \multicolumn{3}{|c|}{$\underline{\text { Data }}$} & \multicolumn{3}{|c|}{ Calibrated Signaling Model } & \multicolumn{3}{|c|}{$\frac{\text { Calibrated CI Model }}{\text { with Conduct }}$} \\
\hline & Pre-JV & Post-JV & Change & Pre-JV & Post-JV & Change & Pre-JV & Post-JV & Change \\
\hline \multicolumn{10}{|c|}{ IQR of Prices } \\
\hline $\mathrm{BL}$ & $\$ 0.189$ & $\$ 0.241$ & +0.052 & $\$ 0.189$ & $\$ 0.368$ & +0.180 & $\$ 0.188$ & $\$ 0.220$ & +0.032 \\
\hline ML & $\$ 0.222$ & $\$ 0.256$ & +0.034 & $\$ 0.273$ & $\$ 0.369$ & +0.096 & $\$ 0.249$ & $\$ 0.216$ & -0.033 \\
\hline $\mathrm{CL}$ & $\$ 0.210$ & $\$ 0.244$ & +0.034 & $\$ 0.273$ & $\$ 0.369$ & +0.096 & $\$ 0.249$ & $\$ 0.216$ & -0.033 \\
\hline \multicolumn{10}{|c|}{ AR(1) Regression Coefficients } \\
\hline$\overline{\rho^{B L, B L}}$ & 0.444 & 0.524 & +0.080 & 0.403 & 0.440 & +0.037 & 0.412 & 0.409 & -0.002 \\
\hline$\rho^{M L, M L}$ & 0.402 & 0.483 & +0.081 & 0.408 & 0.439 & +0.031 & 0.407 & 0.413 & +0.006 \\
\hline$\rho^{C L, C L}$ & 0.413 & 0.453 & +0.040 & 0.408 & 0.439 & +0.031 & 0.407 & 0.413 & +0.006 \\
\hline$\rho^{B L, M L}$ & 0.082 & 0.092 & +0.010 & 0.074 & 0.149 & +0.068 & -0.000 & 0.002 & +0.003 \\
\hline$\rho^{B L, C L}$ & 0.066 & 0.095 & +0.029 & 0.074 & 0.149 & +0.068 & -0.000 & 0.002 & +0.003 \\
\hline$\rho^{M L, B L}$ & 0.059 & 0.087 & +0.028 & 0.046 & 0.154 & +0.108 & 0.004 & -0.000 & -0.005 \\
\hline$\rho^{C L, B L}$ & 0.042 & 0.080 & +0.038 & 0.046 & 0.154 & +0.108 & -0.002 & -0.000 & +0.002 \\
\hline
\end{tabular}

Notes: $\mathrm{BL}=$ Bud Light, $\mathrm{ML}=$ Miller Lite and $\mathrm{CL}=$ Coors Light. The calculation of the data statistics is explained in Section 4.2, with the model predictions based on simulating 10,000 periods of data. Pre-JV averages are calculated for 45 markets, and post-JV averages are calculated for 44 markets, as one market does not have at least 5 stores observed in consecutive weeks after the JV. The CI Model simulations use the parameter estimates from Table 6. column 7, which assumes CI Nash pricing before the JV, but that after the JV the firms use a conduct parameter of 0.15. These assumptions predict average BL and ML prices of post-JV $\$ 10.62$ and $\$ 10.46$, which are almost identical to those predicted by the signaling model for the same demand system.

in the slope of the pricing functions is also consistent with a significant increase in the rate of cost pass-through. After the JV, a 60 cent increase in BL's unobserved cost raises BL's expected price by around 85 cents, compared to 40 cents before the JV.

We can also compare predicted and observed changes in price dynamics. Table 9 compares the cross-market averages of the IQR and $\rho$ parameter statistics before and after the JV in the data, and the values predicted by the column (1) model. We also report the predicted values for the CI model when we assume that, after the JV, the firms use first-order conditions with a "conduct parameter" weight of 0.15 on the profits of their rivals. This weight is chosen so that the CI model predicts the same increase in BL and ML/CL price levels as the signaling model. The signaling model correctly predicts the sign of the changes in each of the reported 
statistics (i.e., more post-JV variation in prices and more own-brand and cross-brand serial correlation), which is an encouraging result given that the calibration uses no post-JV data. On the other hand, the CI-conduct model, which was also unable to match the cross-brand $\rho$ s in the pre-JV data, predicts that the dispersion of prices for BL and ML/CL should move in opposite directions, and that the $\mathrm{AR}(1)$ coefficients should hardly change at all.

\section{Conclusion}

Mailath (1989) showed that when duopolists have private information about marginal costs in a two-period model, first period equilibrium prices can rise as they simultaneously signal. The subsequent empirical and antitrust literatures have ignored how this mechanism can affect prices, likely because it has been presumed that the small amounts of private information could only have small effects on prices. This presumption is flawed, because of feedback loops, where, within a period, signaling by one firm can cause rivals to raise their prices even more, and where it becomes more attractive to invest in signaling when rivals will be signaling in the next period. We find that, in multi-period and infinite horizon games, the price effects of even small amounts of private information can be large in concentrated industries, and that they could lead to mergers being much more harmful for consumers than a CI Nash model would predict.

In the context of the beer industry, we find that our model can explain observed changes in price levels after the MillerCoors joint venture, and that it can also explain changes in price dynamics and cost pass-through which proposed models of collusion or changes in conduct cannot. An important direction for future empirical research is to understand whether other 
mergers have been accompanied by changes in dynamics and pass-through, which could provide a new window into testing different models of post-merger behavior.

As we focus on merger analysis, it is natural to ask how our model relates to the types of "coordinated" and "unilateral" effects described in the Horizontal Merger Guidelines. The Guidelines' discussion of unilateral effects, and the types of upward pricing pressure and merger simulation analyses that it suggests, considers the pricing incentives of the merged firm when it takes rivals' prices as fixed, and, when modeling equilibrium effects, it assumes that rivals remain on their pre-merger best response functions. In our model, a merger changes how non-merging firms set prices because their strategy choices depend, in part, on how they expect the merged firm to respond.

While coordinated effects are often interpreted as referring only to explicit or tacit collusion (Porter (2020)), Baker and Farrell (2019) and Farrell and Baker (2021) offer a broader definition that includes "non-purposive" theories, such as the non-collusive CI Markov Perfect model of Maskin and Tirole (1988) where asynchronous price-setting leads to prices that differ from Nash. Our model is also in this spirit, although it departs from CI and is consistent with firms changing prices simultaneously. Importantly, these types of models suggest that it may sometimes be appropriate to believe that a CI Nash model will underpredict how much prices will rise after a merger even when an industry has no history of explicit collusion, it does not have all of the features that are often listed as supporting tacit collusion (Ivaldi et al. (2003)), and no documents discuss the types of "off-the-equilibrium path" punishment threats that support higher prices in collusive models. 


\section{References}

Ashenfelter, Orley C, Daniel S Hosken, and Matthew C Weinberg. 2015. "Efficiencies Brewed: Pricing and Consolidation in the US Beer Industry." RAND Journal of Economics, 46(2): 328-361.

Ashenfelter, Orley, Daniel Hosken, and Matthew Weinberg. 2014. "Did Robert Bork Understate the Competitive Impact of Mergers? Evidence from Consummated Mergers." Journal of Law and Economics, 57(S3): S67-S100.

Asker, John, Chaim Fershtman, Jihye Jeon, and Ariel Pakes. 2020. "A Computational Framework for Analyzing Dynamic Procurement Auctions: The Market Impact of Information Sharing." RAND Journal of Economics, 51(3): 805-839.

Athey, Susan, Kyle Bagwell, and Chris Sanchirico. 2004. "Collusion and Price Rigidity." Review of Economic Studies, 71(2): 317-349.

Baker, Jonathan B, and Joseph Farrell. 2019. "Oligopoly Coordination, Economic Analysis, and the Prophylactic Role of Horizontal Merger Enforcement." University of Pennsylvania Law Review, 168: 1985-2018.

Berry, Steven T, and Philip A Haile. 2014. "Identification in differentiated products markets using market level data." Econometrica, 82(5): 1749-1797.

Bonatti, Alessandro, Gonzalo Cisternas, and Juuso Toikka. 2017. "Dynamic Oligopoly with Incomplete Information." Review of Economic Studies, 84(2): 503-546.

Bresnahan, Timothy F. 1982. "The Oligopoly Solution Concept is Identified." Economics Letters, 10(1-2): 87-92.

Bronnenberg, Bart J, Michael W Kruger, and Carl F Mela. 2008. "The IRI Marketing Dataset." Marketing Science, 27(4): 745-748.

Caminal, Ramon. 1990. "A Dynamic Duopoly Model with Asymmetric Information." Journal of Industrial Economics, 38(3): 315-333.

Cho, I.K., and D.M. Kreps. 1987. "Signaling Games and Stable Equilibria." Quarterly Journal of Economics, 102(2): 179-221.

Ericson, R., and A. Pakes. 1995. "Markov-Perfect Industry Dynamics: A Framework for Empirical Work." Review of Economic Studies, 62(1): 53-82.

Farrell, Joseph, and Jonathan B Baker. 2021. "Natural Oligopoly Responses, Repeated Games, and Coordinated Effects in Merger Analysis: A Perspective and Research Agenda." Review of Industrial Organization, 58(2): 1-39.

Fershtman, C., and A. Pakes. 2012. "Dynamic Games with Asymmetric Information: A Framework for Empirical Work." Quarterly Journal of Economics, 127(4): 1611-1661. 
Garmon, Christopher. 2017. "The Accuracy of Hospital Merger Screening Methods." RAND Journal of Economics, 48(4): 1068-1102.

Ivaldi, Marc, Bruno Jullien, Patrick Rey, Paul Seabright, and Jean Tirole. 2003. "The Economics of Tacit Collusion: Final Report for DG Competition, European Commission." IDEI, Toulouse, IDEI Working Paper.

Kaya, A. 2009. "Repeated Signaling Games." Games and Economic Behavior, 66(2): 841854 .

Lau, Lawrence J. 1982. "On Identifying the Degree of Competitiveness from Industry Price and Output Data." Economics Letters, 10(1-2): 93-99.

Mailath, George J. 1987. "Incentive Compatibility in Signaling Games with a Continuum of Types." Econometrica, 55(6): 1349-1365.

Mailath, George J. 1988. "An Abstract Two-Period Game with Simultaneous Signaling: Existence of Separating Equilibria." Journal of Economic Theory, 46(2): 373-394.

Mailath, George J. 1989. "Simultaneous Signaling in an Oligopoly Model." Quarterly Journal of Economics, 104(2): 417-427.

Mailath, George J, and Ernst-Ludwig von Thadden. 2013. "Incentive Compatibility and Differentiability: New Results and Classic Applications." Journal of Economic Theory, 148(5): 1841-1861.

Maskin, Eric, and Jean Tirole. 1988. "A Theory of Dynamic Oligopoly, II: Price Competition, Kinked Demand curves, and Edgeworth Cycles." Econometrica, 571-599.

Mester, Loretta J. 1992. "Perpetual Signalling with Imperfectly Correlated Costs." RAND Journal of Economics, 23(4): 548-563.

Milgrom, P., and J. Roberts. 1982. "Limit Pricing and Entry Under Incomplete Information: An Equilibrium Analysis." Econometrica, 50(2): 443-459.

Miller, Nathan H, and Matthew C Weinberg. 2017. "Understanding the Price Effects of the MillerCoors Joint Venture." Econometrica, 85(6): 1763-1791.

Miller, Nathan H, Gloria Sheu, and Matthew C Weinberg. 2020. "Oligopolistic Price Leadership and Mergers: The United States Beer Industry." Georgetown University.

Nevo, Aviv. 1998. "Identification of the Oligopoly Solution Concept in a DifferentiatedProducts Industry." Economics Letters, 59(3): 391-395.

Olley, G Steven, and Ariel Pakes. 1996. "The Dynamics of Productivity in the Telecommunications Equipment Industry." Econometrica, 64(6): 1263-1297.

Pakes, Ariel, and Paul McGuire. 1994. "Computing Markov-Perfect Nash Equilibria: Numerical Implications of a Dynamic Differentiated Product Model." RAND Journal of Economics, 25(4): 555-589. 
Peters, Craig. 2009. "Evaluating the Performance of Merger Simulation: Evidence from the U.S. Airline Industry." Journal of Law and Economics, 49(2): 627-649.

Porter, Robert H. 2020. "Mergers and Coordinated Effects." International Journal of Industrial Organization, 73: 102583.

Roddie, C. 2012. "Signaling and Reputation in Repeated Games, I: Finite Games." University of Cambridge.

Shapiro, Carl. 1986. "Exchange of Cost Information in Oligopoly." Review of Economic Studies, 53(3): 433-446.

Smith, Anthony. 2008. "Indirect Inference." The New Palgrave Dictionary of Economics, 2nd Edition.

Sweeting, Andrew, James W Roberts, and Chris Gedge. 2020. "A Model of Dynamic Limit Pricing with an Application to the Airline Industry." Journal of Political Economy, 128(3): 1148-1193.

Sweeting, Andrew, Mario Leccese, Xuezhen Tao, and Xinlu Yao. 2022. "Should We Expect Uncertain Merger Synergies to Be Passed Through to Consumers?" University of Maryland.

Toxvaerd, Flavio. 2008. "Strategic Merger Waves: A Theory of Musical Chairs." Journal of Economic Theory, 140(1): 1-26.

Toxvaerd, Flavio. 2017. "Dynamic Limit Pricing." RAND Journal of Economics, 48(1): 281-306.

Vives, Xavier. 2011. "Strategic Supply Function Competition with Private Information." Econometrica, 79(6): 1919-1966. 